\title{
Bulk Ultrafine-Grained Magnesium Alloys by SPD Processing: Technique, Microstructures and Properties
}

\author{
Jinghua JIANG and Aibin MA \\ Hohai University \\ P.R.China
}

\section{Introduction}

$\mathrm{Mg}$ alloys are very attractive as the lightest metallic structural materials and have great potential for applications in automotive, aerospace and electronic industries. However, their usages are still limited due to some undesirable properties of castings (such as strength, ductility, creep and corrosion resistance) and few fabricating methods besides conventional ingot metallurgy processing. Since grain refinement is generally believed to have beneficial effect on properties of $\mathrm{Mg}$ alloys, fabrication of bulk ultrafine-grained (UFG, grain size less than $1 \mu \mathrm{m}$ ) alloys using the new conceptual metal forming process - severe-plasticdeformation (SPD) should attract considerable attention (Azushima et al., 2008).

During the last decade, SPD processing has been evolving as a rapidly progressing direction of modern materials science that is aimed at developing materials with new mechanical and functional properties for advanced applications. As well known, all $\mathrm{Mg}$ alloys (except for some special Li-containing alloys) exhibit a hexagonal crystal structure, leading to severe limitations in their ductility, strength and creep resistance. This inherent difficulty maybe be reasonably overcame by some special processing of SPD, such as equal-channel angular pressing (ECAP), accumulative rolling bonding (ARB), high pressure torsion (HPT), etc. Enhanced properties have been obtained after these SPD processes in various $\mathrm{Mg}$ alloys. For example, ZK60 Mg alloy processed by ECAP (with the grain size to $\sim 0.8 \mu \mathrm{m}$ ) is superplastic at a testing temperature of $473 \mathrm{~K}$ with an optimum ductility of $\sim 1310 \%$ when using an initial strain rate of $2.0 \times 10^{-4} \mathrm{~s}^{-1}$ (Figueiredo et al., 2006). Mg-9Li-1Zn alloy had the greater increase in tensile strength of about $41.8 \mathrm{MPa}$ and the least decrease in elongation of about $25 \%$ at room temperature (Chang et al., 2006). UFG ZE41A alloy after enough ECAP passes obtains higher corrosion resistance besides superior mechanical properties (about 120\% higher in yield strength and 75\% larger in elongation at room temperature after 32 passes) (Ma et al., 2009).

SPD fabrication of bulk UFG Mg alloys is becoming one of the most actively developing areas in the field of advanced structural and functional $\mathrm{Mg}$ alloys. SPD-produced UFG materials are fully dense and their large geometric dimensions make them attractive for efficient practical applications. Today, SPD techniques are emerging from their domain of laboratory-scale research into commercial production of various UFG materials (Valiev et al., 2009). In this chapter, we will consider these new trends in SPD processing used to produce bulk UFG Mg alloys and highlight some key results on the development of the 
UFG alloys science and applications. The aim is to better understand the relationships between microstructure and properties of SPD materials, and exploit novel SPD processing routes for fabricating UFG Mg alloy with enhanced properties.

\section{Developing SPD techniques for grain refinement}

SPD processes may be defined as metal forming processes to fabricate UFG materials, via introducing an ultra-large plastic strain into a bulk metal without any significant change in the overall dimensions. The main objective is to produce lightweight parts with high mechanical behaviours and environmental harmony, since the well accepted notion of the Hall-Petch equation suggests that a decrease in grain size leads to an increase in yield strength. Due to an ever-increasing interest in fabricating materials with extremely small grain sizes, various SPD techniques are now available, including ECAP, ARB, HPT, cyclic extrusion compression (CEC), repetitive corrugation and straightening (RCS), torsion extrusion, severe torsion straining (STS), cyclic closed-die forging (CCDF), super short multi-pass rolling (SSMR), etc. We report here the principles and new trends of those major SPD processes, and discuss its application in fabricating UFG magnesium alloys.

\subsection{The principles of SPD techniques}

Equal channel angular pressing, known also as equal-channel angular extrusion (ECAE), was first introduced by Segal et al. (1981) at an institute in Minsk in the former Soviet Union. It is at present the most developed SPD processing technique, which may be used for grain refinement of solid metals billet and consolidation of metallic powder to obtain new and unique properties. Fig.1 shows the schematic representation of ECAP process and a typical facility (Berbon et al., 1999). During ECAP a rod-shaped billet is side extruded through a die constrained within a channel that is bent at an abrupt angle. Since the cross-sectional dimensions of the billet remain unchanged, the pressings may be repeated to attain exceptionally high strains. The equivalent strains, $\varepsilon$ introduced in ECAP is determined by a relationship as follows (Iwahashi et al., 1996):

$$
\varepsilon=\frac{N}{\sqrt{3}}\left\{2 \cot \left(\frac{\phi}{2}+\frac{\psi}{2}\right)+\psi \operatorname{cosec}\left(\frac{\phi}{2}+\frac{\psi}{2}\right)\right\}
$$

where $N$ is the pass number through the die, $\phi$ is the angle of intersection of two channels and $\psi$ is the angle subtended by the arc of curvature at the point of intersection. When $\phi=$ $90^{\circ}$ and $\psi=0^{\circ}$, the total strain from the above equation is $\varepsilon=1.15 \mathrm{~N}$. During repetitive pressing, the shear strain is accumulated in the billet, leading ultimately to a UFG structure. For these billets inserted within the channel, it is convenient to develop processing routes in which the billets are rotated by increments of $90^{\circ}$ between each separate pass. This leads four fundamental process of metal flow during ECAP, as shown in Fig.2. In route A, the billet is pressed without rotation. In route $B_{A}$ and $B_{C}$, the billet is rotated by $90^{\circ}$ in an alternate direction or the same direction between consecutive passes, respectively. In route $\mathrm{C}$, the sample is rotated by $180^{\circ}$ between consecutive passes. From these macroscopic distortions shown in Fig.2, the influence of the processing route on the development of an UFG microstructure can be considered. When using a die with $\phi=90^{\circ}$, route $\mathrm{B}_{\mathrm{C}}$ is generally the most expeditious way to develop a UFG structure consisting of homogeneous and equiaxed grains with high angle grain boundaries. Matsubara et al. (2003) and Lin et al. 
(2005) fabricate the UFG Mg alloys via a two-stage extrusion plus ECAP. The original coarse grain size can be reduced to around $0.7 \mu \mathrm{m}$ after extrusion at $300^{\circ} \mathrm{C}$ and subsequent 8 -pass ECAP at $200^{\circ} \mathrm{C}$. There has been numerous recent modification of conventional ECAP that are designed to yield more efficient grain refinement (Valiev \& Langdon, 2006), including the incorporation of a backpressure and the development of continuous ECAP processing.
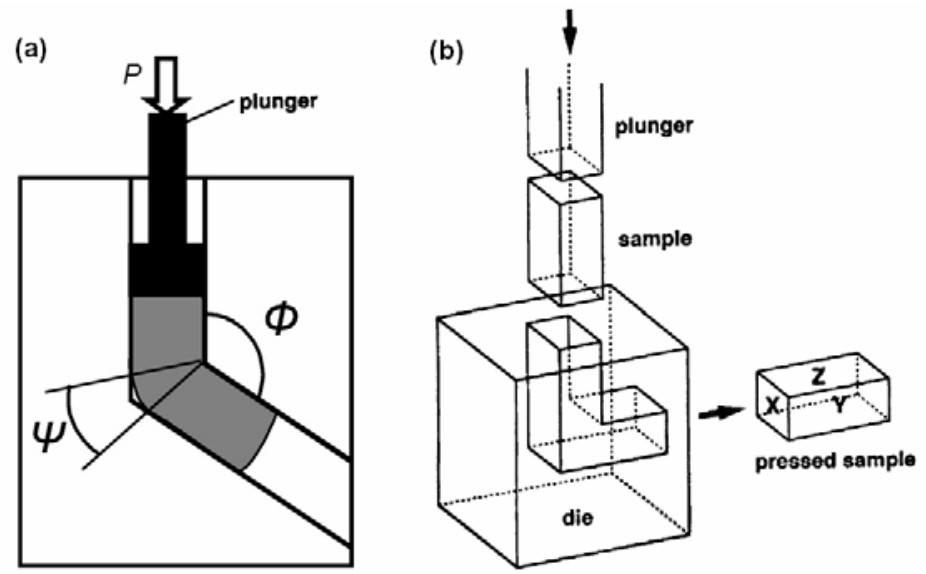

Fig. 1. Schematic illustration of ECAP process (a) and a typical facility (b): the $X, Y$ and $Z$ planes denote the transverse plane, the flow plane and the longitudinal plane, respectively.
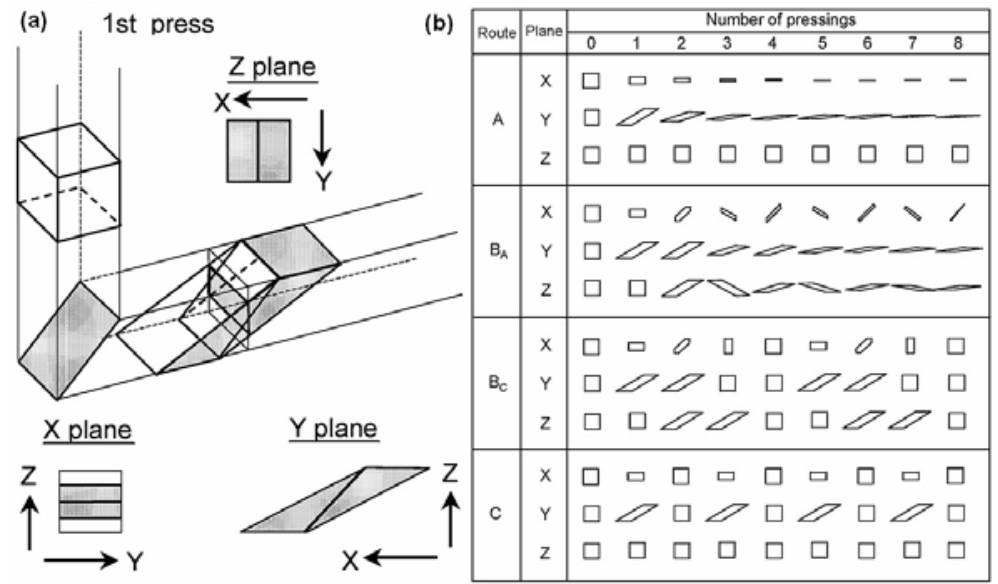

Fig. 2. Fundamental process of metal flow during ECAP. (a) The deformation of a cubic element on a single pass (a Furukawa et al, 2001) . (b) Shearing characteristics for four different processing routes (Furukawa et al, 1998).

Accumulative roll-bonding process was first developed by Saito et al. (1998), which principle is represented systematically in Fig.3. First, a sheet is rolled to reduce one-half of the thickness in a prerolled condition, and then cut into two halves that are stacked together. Their 
interfaces are surface-treated in advance to enhance the bonding strength. The stacking sheets are then rolled again to one-half thickness and sectioned into two halves again. Conventional roll-bonding, cutting, pre-treating and stacking of sheets are repeated in the process, so that very large plastic strain can be accumulated in the sheet. The strain after $\mathrm{n}$ cycles of the ARB process can be expressed as $\varepsilon_{\mathrm{N}}=0.80 \mathrm{~N}$ (Saito et al. ,1999). This process has recently been applied successfully for dramatic grain refinement of AZ61 Mg alloy (Del Valle et al., 2005). ARB process is applicable to produce large sheet of bulk UFG Mg alloys. However, the UFG structure produced by ARB is not three-dimensionally equiaxed but rather there is a pancake-like structure elongated in the lateral direction.

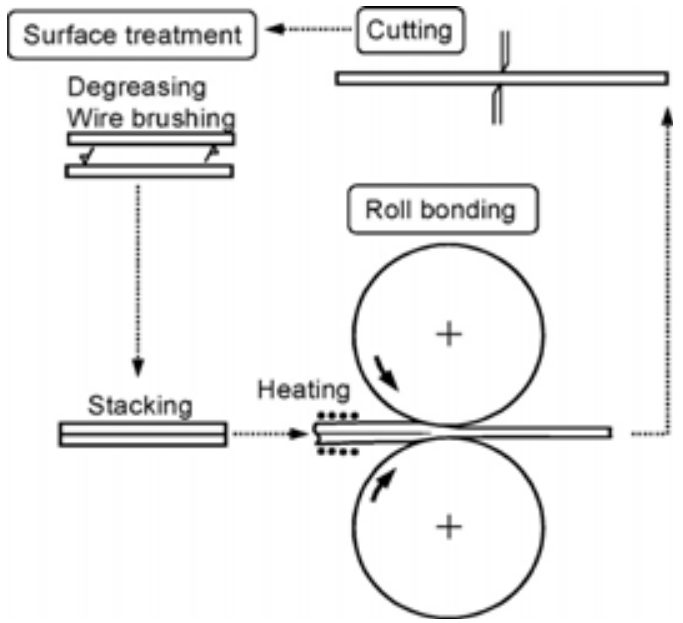

Fig. 3. Diagrammatic representation of the accumulative roll-bonding (Saito et al. ,1999)

High-pressure torsion (HPT) process refers to the processing of metals whereby samples, generally in the form of a thin disk, are subjected to a compressive force and concurrent torsional straining (Bridgman et al., 1935).The principle of HPT is illustrated schematically in Fig.4. The disk located in a closed die is compressed by a very high pressure, and plastic torsional straining is achieved by rotation of one of the anvil. The equivalent strain according to the von Mises yield criterion is given by

$$
\varepsilon=\frac{2 \pi n r}{\sqrt{3} l}
$$

where $r$ is the distance from the axis of the disk sample, $n$ is the number of rotation and $l$ is the thickness of the sample. For Mg alloys which are not processed easily by ECAP, HPT is more effective in producing exceptionally small grain sizes (Zhilyaev \& Langdon., 2008). This process provides an opportunity for achieving significant grain refinement, often to the $\mathrm{nm}$ level, and exceptionally high strength. The disadvantages of the conventional HPT are that the relatively small disk is not available for the production of large bulk materials, and the microstructures created are dependent on the applied pressure and the location within the disc. It is reasonable to anticipate that HPT processing may be an effective tool for producing small parts used in a range of industrial and medical applications. 


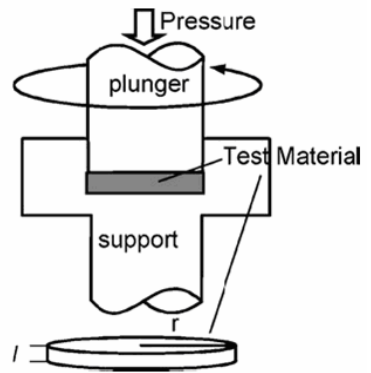

Fig. 4. Diagrammatic representation of the thin disc-HPT process (Valiev et al. ,1991)

Cyclic extrusion compression process is performed by pushing a billet from one cylindrical chamber of diameter $\mathrm{D}$ to another with equal dimensions through a die with diameter $\mathrm{d}$ (markedly smaller than D), which principle is represented schematically in Fig. 5. The billet is extruded repeatedly backwards and forwards within the chamber, and preserves the original shape with large strain deformation after $\mathrm{N}$ passes. The accumulated equivalent strain is approximately given by

$$
\varepsilon=4 N \ln (D / d)
$$

where $\mathrm{N}$ is the number of deformation cycles, $\mathrm{D}$ is the chamber diameter and $\mathrm{d}$ is the channel diameter. This process is better suited for processing soft material such as $\mathrm{Mg}$ alloys. However, the strain introduced in the forward extrusion may be cancelled by the strain introduced on the backward extrusion. The strains reached with this process are much high than those with any unidirectional SPD technique, but the microstructure are similar for extra dislocation annihilation due to cyclic straining character (Richert et al., 2003 ).

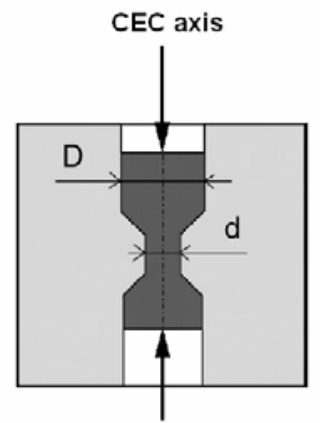

Fig. 5. Schematic illustration of cyclic extrusion compression process

SPD processing has been developed extensively over the last decade and the polycrystalline $\mathrm{Mg}$ alloys produced by various SPD techniques exhibit unique and attractive characteristics including excellent strength at ambient temperature. Although those techniques have been typically used for laboratory-scale research, materials processed by SPD are now receiving serious consideration for potential use in a wide range of products. For successful commercialization of UFG materials, the requirement of economically feasible production is necessary and raises several new problems in the development of SPD techniques. 


\subsection{Continuous SPD pressing}

It is known that UFG materials with unique mechanical and physical properties can be produced by SPD, and the key to the wide commercialization is to lower their processing cost and waste through continuous processing. Although ECAP is an effective route to UFG billets by imposing large shear strains, the conventional process has some limitations for commercialization. In particular, the limited length of the billets makes ECAP a discontinuous process with low production efficiency and high cost. Several attempts have been made to develop continuous SPD processes, such as rotary-die ECAP (Nishida et al., 2001), equal channel angular drawing (ECAD) (Alkorta et al., 2002), continuous cyclic bending (CCB) (Takayama et al., 2002 ), repetitive corrugation and straightening (RCS) (Huang et al., 2001), continuous shear deformation process (conshearing) (Saito et al., 2000), continuous confined strip shearing (C2S2) (Lee et al., 2002), continuous frictional angular extrusion (CFAE) (Huang et al., 2007 ), ECAP-Conform(Raab et al., 2004) . The ARB and RCS process using a rolling mill are effective to continuously manufacture UFG sheets or plates; however, the bad quality of interface bonding, poor ductility or edge-cracks need be eliminated for industrial application. Although the total strain can be largely accumulated in CCB, UFG microstructures have not been developed (Tsuji et al., 2003 ) .

Fig. 6 presents the schematic illustration of a rotary-die (RD) ECAP process. The die contains two channels with the same cross-sections intersecting at the center to remove the limitation in the conventional ECAP, i.e. the sample must be removed from the die and reinserted again in each step. By the RD-ECAP apparatus, a billet can be repetitive pressed with a back pressure. Ma et al. (2009) reported that the UFG ZE41A Mg alloy after 16 passes of RDECAP is more uniform with average grain size of about $1.5 \mu \mathrm{m}$. In the similar way, Rosochowski et al. (2002) developed a method to reduce the repetitive number by increasing the number of channel turns in the die. These ECAP processes have been used only in the laboratory for low productivity, and continuous ECAP processing techniques (e.g. ECAD, conshearing and C2S2) are developed for mass production of long metal bars and strips. However, ECAD cannot be use effectively for multi-pass processing due to cross-sectional reduction higher than 15\% (Alkorta et al., 2002). A schematic illustration of the C2S2 machine used for continuous confined strip shearing is presented in Fig.7. This newly developed technique was termed dissimilar channel angular pressing (DCAP) to distinguish this technique with the conventional ECAP. The DCAP process can impart the shear deformation to long and thin metallic sheets without significant changes in their crosssectional area (Lee et al., 2001; Lee et al. , 2002). However, these techniques should be developed for further improvement of microstructure uniformity and properties.

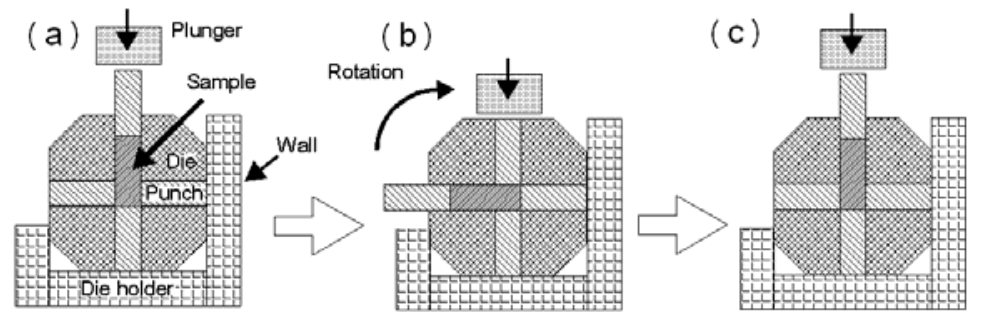

Fig. 6. The RD-ECAP process via pressing route A: (a) initial state, (b)after one pass and (c) after $90^{\circ}$ die rotation 


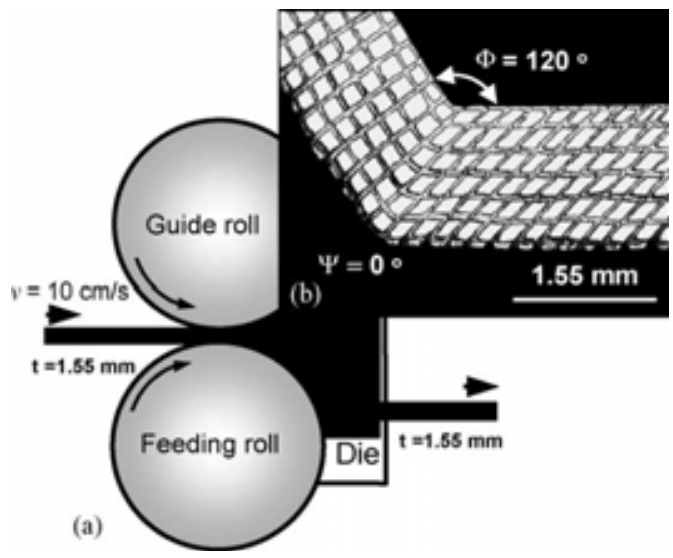

Fig. 7. (a) A schematic illustration of the C2S2 machine used for continuous confined strip shearing based on DCAP; (b) optical micrograph showing the shear deformation pattern recorded from the side surface of the specimen processed by DCAP (Han et al,2004).

Recently, the combining ECAP with the Conform process (Raab et al, 2004) is developed to continuously process UFG materials for large-scale commercial production. The principle of the ECAP-conform process is represented schematically in Fig.8. The workpiece is driven forward by frictional forces on the three contact interfaces with the groove. The workpiece is constrained to the groove by the stationary constraint die, which forces the workpiece turn by shear deformation as in a regular ECAP process. The continuous nature of the process makes it promising for successfully producing UFG materials on a large scale, in an efficient and coat-effective manner. However, further study is necessary to investigate its ability with respect to grain refinement and properties improvement of various UFG materials.

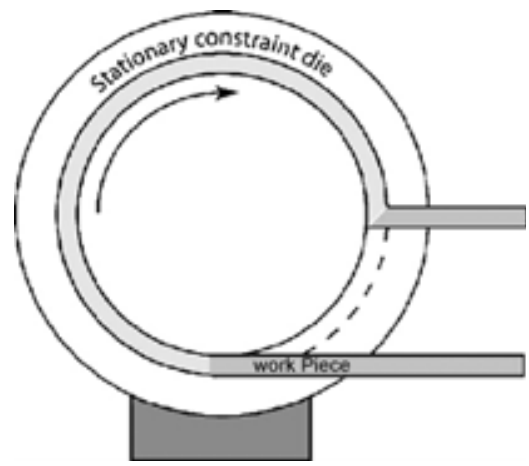

Fig. 8. Schematic illustration of the ECAP-Conform process.

\subsection{Combined SPD processing}

Recently, the combined processes of ECAP and conventional metal forming ( such as cold rolling, forging or extrusion ) were developed to improve properties of UFG materials with effective shaping of long-sized semi-products (sheets, rods). The principle of the combined process of ECAP and cold rolling is represented schematically in Fig. 9 (Azushima et al., 
2002). Cheng et al. (2007) used the process of equal-channel angular rolling (ECAR) to produce AZ31 Mg alloy sheets with improved ductility. The high-speed-ratio differential speed rolling (HRDSR) technique was developed to induce a large shear deformation in an $\mathrm{Mg}$ sheet during rolling. By this technique, UFG Mg alloy sheets with a low intensity of basal fiber texture could be produced and obtained with high strength and high ductility (Kim et al., 2007). By applying ECAR and HRDSR in sequence, one can effectively control the grain size and texture of AZ31 sheets, resulting in the increase of its strength and ductility (Kim et al., 2009). This shows great prospects for applying SPD processing to commercial production of UFG Mg alloys.

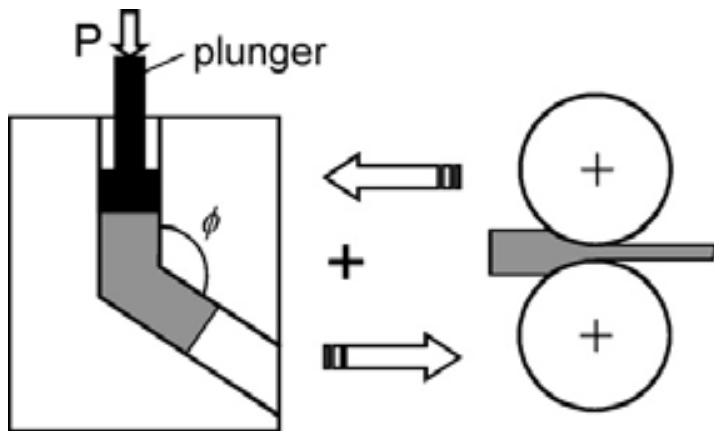

Fig. 9. Principle of the combined process of ECAP process and cold rolling.

\section{Structural features and deformation behaviors in SPD-produced bulk UFG Mg alloys}

Bulk UFG Mg alloys produced by SPD techniques have been arguably the hottest research area in the recent years (Máthis et al., 2005), because UFG materilas have sufficient room temperature ductility and superplasticity at high strain rates (Weertman et al., 1999). Although the successful attainment of UFG pure Mg by SPD is very difficult due to a limit of slip systems in hexagonal close-packed (hcp) systems, it is possible to obtain remarkable grain refinement in Mg-based alloys. An early attempt to achieve significant grain refinement in AZ91 alloy by ECAP was successful, which obtained a grain size of $1 \mu \mathrm{m}$ with an elongation of $660 \%$ at $6 \times 10^{-5} \mathrm{~s}^{-1}$ and $200{ }^{\circ} \mathrm{C}$ (Mabuchi et al., 1997). Ma et al. (2009) found that the tensile yield strength, ultimate strength, elongation to failure of UFG ZE41A Mg alloy are all remarkably increased after a large number of ECAP passes. However, the combination of high strength and good ductility is rare in their coarse-grained counterparts. It is well known that the mechanical behaviors of materials are determined by their deformation mechanisms, while the deformation mechanisims are controlled by the structures of the materials. The unique mechanical behaviors of UFG Mg alloys are believed to be caused by the unique deformation mechanisims operating in the UFG materials.

\subsection{Structural evolution during SPD processes}

Jin et al (2006) investigated the microstructure evolution of AZ31 Mg alloy ECAP-processed at $498 \mathrm{~K}$ to clarify the process of grain refinement. SEM examinations showed that the grains of AZ31 Mg alloy were refined significantly with the mean grain size of $1.91 \mu \mathrm{m}$ after 
extruded eight passes (in Fig.10). TEM examination revealed that after the first pass, the structure comprises a mixture of sub-boundaries, low angle grain boundaries (LAGBs) and high angle grain boundaries (HAGBs, misorientation angle $>15^{\circ}$ ). Dislocations were induced at the initial stage of extrusion and rearranged to form dislocation boundaries and sub-grain
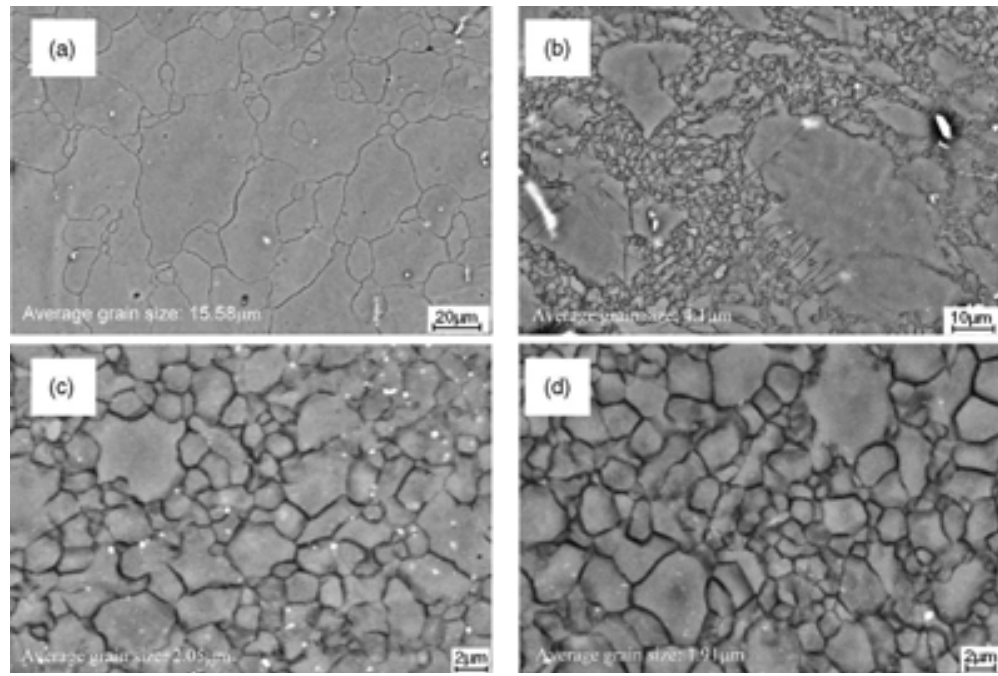

Fig. 10. SEM photographs of AZ31 alloy: (a) original condition, (b) after one pass, (c) after four passes and (d) after eight passes of ECAE at temperature $498 \mathrm{~K}$.( Jin et al , 2006)

boundaries during deformation (see Fig.11). As strain increased, the newly created dislocations in subgrains were absorbed by the subboundaries and the misorientation between subboundaries increased and evolved to LAGBs and HAGBs. The frequency of LAGBs decreased and the frequency of HAGBs increased from four passes to eight passes, however the grain sizes have not been changed (see Fig.10 c and d). It means that grain refinement of ECAPed AZ31 alloy is pronounced at the initial stage of ECAP and further deformation forms more HAGBs but does not provide further refinement.

Precipitate-hardened Mg alloys or Mg-based composites can easily achieve a UFG structure due to the effective pining effect from the precipitates or added ceramic particles on the grain boundaries (Morisada et al, 2006; Lee et al., 2006; Chang et al., 2006). For pure Mg or solute solution hardened Mg alloys (such as AZ31) with a low content of alloying elements, it is difficult to achieve a UFG microstructure due to the rapid growth kinetics of the singlephase grains. Li et al. ( 2004 ) reported that dynamic recrystallization (DRX) caused the grain refinement of ECAPed AZ31 Mg alloy due to the effect of the deformation temperature and the total strain or the strain rate occurred in the SPDed material. The SPD process led to homogeneous equiaxed grains and many small subgrains, so that the microstructure became finer and more homogeneous with increasing ECAP passes up to a critical value. The effect of deformation temperature is significant as high temperature is favorable for grain growth. The DRX grain size is finer corresponding to the lower ECAP temperature. Ma et al.(2009)observes microstructure characterization of the ZE41 alloy after various ECAP passes at $603 \mathrm{~K}$. As shown in Fig. 12, primary as-cast ZE41 alloy has equiaxed grains with the size of around $80 \mu \mathrm{m}$. The alloyed elements of $\mathrm{Zn}$ and $\mathrm{RE}$ exist as $\mathrm{Mg}_{12} \mathrm{Zn}_{13}$ and $\mathrm{REMg} \mathrm{gg}_{12}$ 


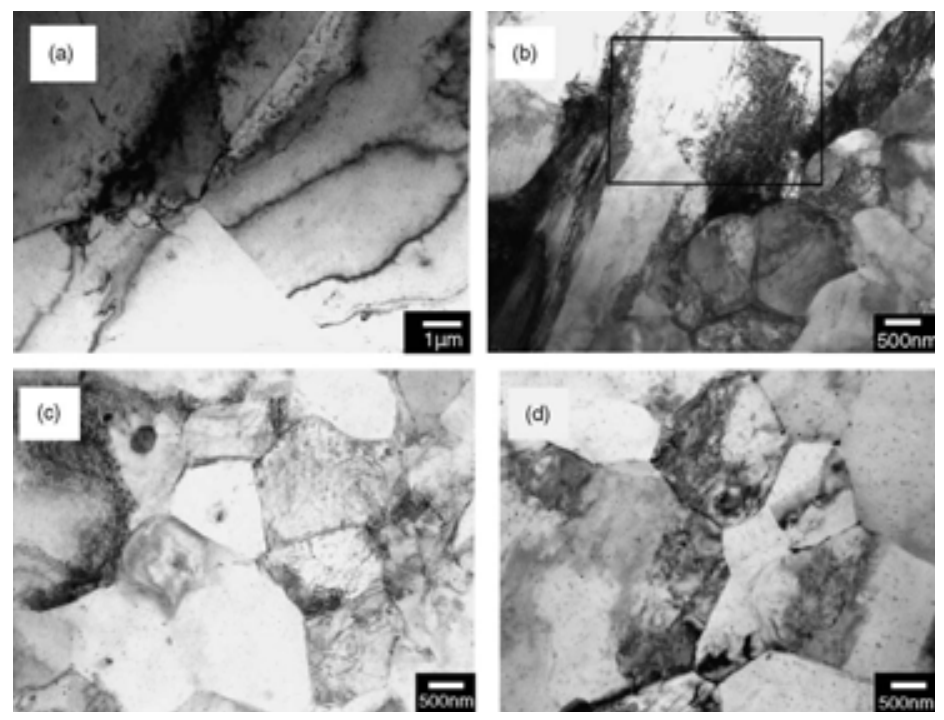

Fig. 11. TEM photographs of as-extrusion and ECAP AZ31 alloy, (a) as-extrusion, (b) ECAP one pass at $498 \mathrm{~K},(\mathrm{c})$ ECAP four passes at $498 \mathrm{~K}$ and (d) ECAP eight passes at $498 \mathrm{~K}$.

compounds at $\mathrm{Mg}$ grain boundaries at room temperature, while zirconium crystals are also concentrated at the grain boundaries (Avedesian et al., 1999). After 8 passes of ECAP, the structure is formed by large particles or large long grains with $70 \mu \mathrm{m}$ in length, and ultrafine grains or particles (about $1 \mu \mathrm{m}$ in diameter). The large long grains take more percentage compared with ultra-fine grains in the 8-passes sample. Obviously, DRX of Mg alloys plays a key role in refining grains into sub-micrometer range. The more the pressing pass, the higher the degree of deformation and the greater the amount of recrystallization finished. After 16 passes of pressing, the microstructure of this alloy shows ultrafine Mg grains but includes a few large particles with $5-8 \mu \mathrm{m}$ in size. As increasing the ECAP passes to 32 , this alloy possess a complete recrystallization microstructure, which is more uniform with average grain size of about $1.5 \mu \mathrm{m}$ and no large particle or large grain is found. With further ECAP processing at the same temperature, grain size remains stable.

Accumulative roll bonding is also proved to be an efficient and inexpensive grain refinement method for Mg-Al-Zn alloys (Perez-Prado et al., 2004 ) . The final grain size obtained is similar to that achieved by other SPD techniques such as ECAP (Mabuchi et al., 1999). Increasing the Al content results in finer microstructures, albeit more heterogeneous. Several examples of the beneficial effects of precipitation in the stabilization of ultrafine grains via SPD are given in the literature (b Furukawa et al., 2001). Second, a larger Al content in solution retards the movement of dislocations, hindering recovery, and this may also result in finer grains. Thus, the homogeneity of the microstructure can be improved by increasing the number of rolling passes.

Grain orientation distribution (texture) plays an important role in improving mechanical properties of the hexagonal metals and alloys (Mukai et al., 2001; Agnew et al., 2004), because these materials usually have quite high plastic anisotropy in their single crystals. Thus the textures in the hexagonal alloys after the ECAP processing were investigated carefully. It is known that moderate to strong level of complex textures can be 


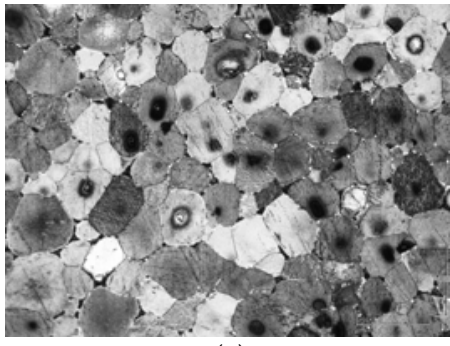

(a)

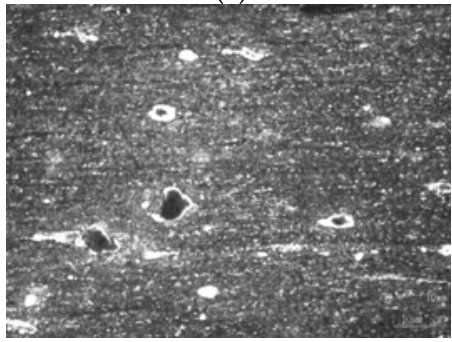

(c)

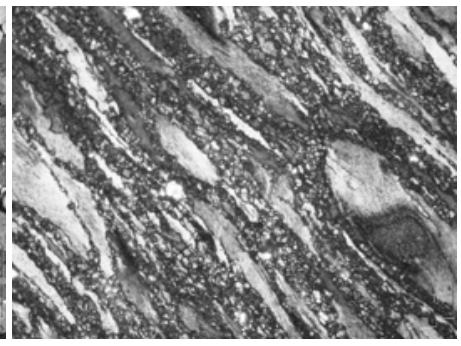

(b)

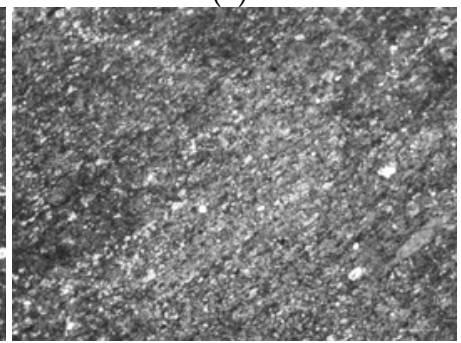

(d)

Fig. 12. Optical microstructures of the ZE41 alloy before and after ECAP: (a) as-cast alloy; (b) 8 passes; (c) 16 passes; (d) 32 passes of pressing.

induced during various deformation routes available in ECAP (Ferrase et al., 2004 ) . Liu et al. (2004) reported that ECAP can not only refine the grain size, but also modify the texture type of the $\mathrm{Mg}-3.3 \% \mathrm{Li}$ alloy. Two quite different and strong textures are formed in the $\mathrm{Mg}-$ $3.3 \% \mathrm{Li}$ alloy after the two ECAP processes with the routes $\mathrm{A}$ and Bc (see in Fig.13). Recrystallization occurs during both the ECAP processes, but the extents of recrystallization are different for route $\mathrm{A}$ and $\mathrm{Bc}$. The combined effect of grain refinement and texture modification caused by ECAP can improve the strength and ductility of the alloy simultaneously.
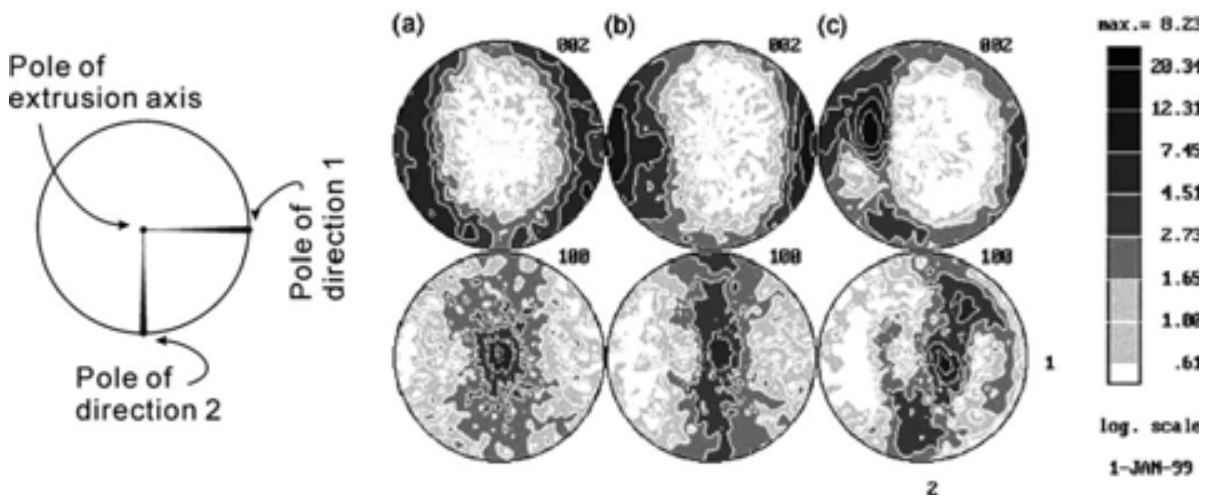

Fig. 13. (002) and (100) pole figures of Mg-3.3\% Li alloy for (a) conventionally extruded samples, (b) 4-passes ECAP by A routes and (c) 4-passes ECAP by Bc routes (Liu et al.,2004). 
Del Valle et al.(2006) reported that the texture and grain size has a great influence on work hardening and ductility of polycrystalline Mg alloy after SPD process. In addition to the direct effect of texture through the change in the orientation factor for basal and prismatic slip, effects were found on dynamic recovery and the appearance of stage II of work hardening. Dynamic recovery is enhanced with increasing deviation of the basal planes from the ideal orientation. The grain size refinement causes a strong decrease in the hardening rate due to a contribution of grain boundary sliding to deformation.

Recently, Gan et al.( 2009) presented the texture evolution in pure Mg for ECAP processing between one and four passes, along with the associated pole figures. Yapici et al. (2009) investigated the texture evolution of four different hexagonal close packed materials (pure $\mathrm{Zr}$, pure Be, AZ31 Mg alloy and Ti-6Al-4V) after varies passes of ECAP. The resulting textures demonstrated a common feature where the basal poles were aligned along the most highly elongated direction of the sheared grains. Their texture evolutions is striking similar, irrespective of the initial material properties (c/a ratio, impurity content, grain size, texture) and processing conditions. It is suggested that basal slip acts as the common plasticity mechanism leading to the similar texture evolutions. Therefore, UFG Mg alloys with optimum mechanical properties can be realized faster by reducing-cost processing experiments and texture measurements.

\subsection{Enhanced mechanical properties by SPD processing}

Grain refinement is an effective method to improve mechanical behaviours of $\mathrm{Mg}$ alloys at room temperature (Valiev et al., 2000; Zheng et al., 2008 ), because Hall-Petch slope in $\mathrm{Mg}$ alloys is very pronounced $\left(210 \pm 60 \mathrm{MPa} \mu \mathrm{m}^{1 / 2}\right.$ vs. $115 \mathrm{MPa} \mu \mathrm{m}^{1 / 2}$ in $\mathrm{Al}$ alloys) (Jones et al., 1998). However, the studies on the effect of grain size on the properties of ECAPed Mg-Li alloys indicate that the UFG alloys exhibit the inverse Hall-Petch relation (Kim et al., 2009), due to a transition from power-law breakdown (grain boundary diffusion-controlled GBS) to a grain-size-independent mechanism (pipe diffusion-controlled slip creep). An interesting ductility enhancement at room temperature in UFG Mg alloys has been attributed to the texture changes produced by SPD (Mukai et al., 2001). Obviously, both grain refinement and texture modification have great influence on mechanical properties in $\mathrm{Mg}$ alloys (Agnew et al., 2004) .

Tong et al. (2009) investigated mechanical properties of UFG Mg-5.12 wt.\% Zn-0.32 wt.\% Ca alloy produced by 4 -passes ECAP at $250^{\circ} \mathrm{C}$ (average grain size : $0.7 \mu \mathrm{m}$ ). The ECAPed alloy exhibited lower yield stress and ultimate tensile strength at room temperature, indicating that the texture softening effect was dominant over the strengthening from grain refinement. The ductility of the ECAPed alloy was increased to $18.2 \%$, and the grain refinement caused an obvious decrease in work hardening rate. The elongation was improved in the ECAPed Mg-Zn-Ca alloy with lower work hardening, which was different from some ECAPed Mg alloys with grain size larger than $2 \mu \mathrm{m}$. These alloys showed high elongation with high work hardening rate (Agnew et al., 2004; Ko et al., 2006). This suggested that grain size plays a major role in the strain hardening behavior of ECAPed $\mathrm{Mg}$ alloys compared with the texture effect. The improved tensile elongation in the ECAPed alloy may be attributed to non-basal slip and grain boundary sliding (GBS), in addition to basal slip. a Koike et al.(2003) reported that non-basal slip was induced in fine grained $\mathrm{Mg}$ alloys by compatibility stress that operated to maintain continuity at grain boundaries. Thus, the activity of non-basal slip near grain boundaries would be helpful for the 
improvement of ductility in the ECAPed Mg alloy. GBS was observed to occur at room temperature in AZ31 alloy with average grain size of $8 \mu \mathrm{m}$, and the ratio of the strain by GBS to total strain is about $8 \%$ (b Koike et al.,2003). Therefore, the GBS might be also responsible for deformation of the ECAPed alloy at room temperature.

Ma et al. (2009) found that ECAPed ZE41A aeronautic Mg alloy for 8 passes at 603K has higher tensile strength but relatively lower ductility than the unpressed sample from room temperature to $423 \mathrm{~K}$ (see in Fig.14), whereas the tensile yield strength, ultimate strength, elongation to failure of UFG alloy after enough passes are all remarkably increased (about $120 \%$ higher in yield strength and 75\% larger in elongation at RT after 32 passes). The UFG $\mathrm{Mg}$ alloy pressed at elevated temperature underwent DRX, resulting in more uniform

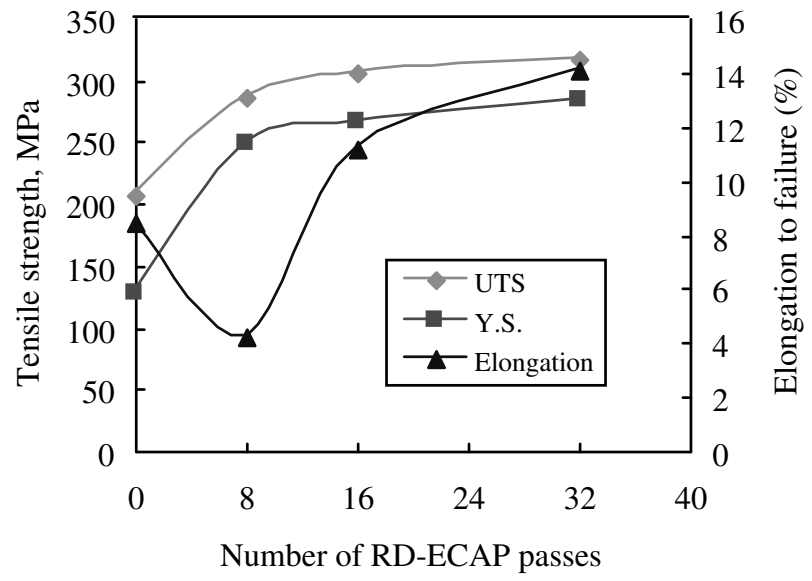

Fig. 14. Tensile strength and plasticity of ZE41A Mg alloy at room temperature as a function of the number of ECAP passes:

$\alpha$ phase with average grain size of about $1.5 \mu \mathrm{m}$. The simultaneous improvement of its strength and ductility at service temperature was due to higher fraction of high-angle grains boundaries combined with a low dislocation density.

The high fraction of HAGB introduced by SPD make microstructure of UFG Mg alloy conducive to the occurrence of GBS and thus to the advent of superplastic flow. It was shown in Fig.15 that the 1\%Ca-AZ80 Mg alloy produced by HRDSR (average grain size: $0.8 \mu \mathrm{m}$ ) exhibits a maximum elongation of $\sim 700 \%$ at $0.3 \times 10^{-3} \mathrm{~s}^{-1}$ at $523 \mathrm{~K}$ ( Kim et al., 2010). Excellent low-temperature superplasticity $(<573 \mathrm{~K})$ was also observed in the ECAPed $\mathrm{Mg}$ alloys: elongations to failure are $810 \%$ and $570 \%$ at a strain rate of $3 \times 10^{-3} \mathrm{~s}^{-1}$ for ZK60 and AZ91 alloys, respectively (Chuvil'deev et al., 2004). These results confirm the potential for utilizing SPD processing in achieving exceptional superplastic ductilities with the SPDprocessed ultrafine microstructure. Currently, superplastic metals are formed industrially within the strain-rate range of $\sim 10^{-3} \mathrm{~s}^{-1}$ to $10^{-2} \mathrm{~s}^{-1}$. Since the strain rate is proportional to $(1 / \mathrm{d})$ 2 , it is apparent that SPD processing and production of bulk UFG Mg alloy has the potential of achieving very rapid superplastic flow and thereby substantially reducing the forming times in industrial operations.

The fatigue properties are key features for a successful use of UFG Mg alloys. Fine-grained materials are known to exhibit a lower resistance of fatigue crack growth. Because the 
(a)
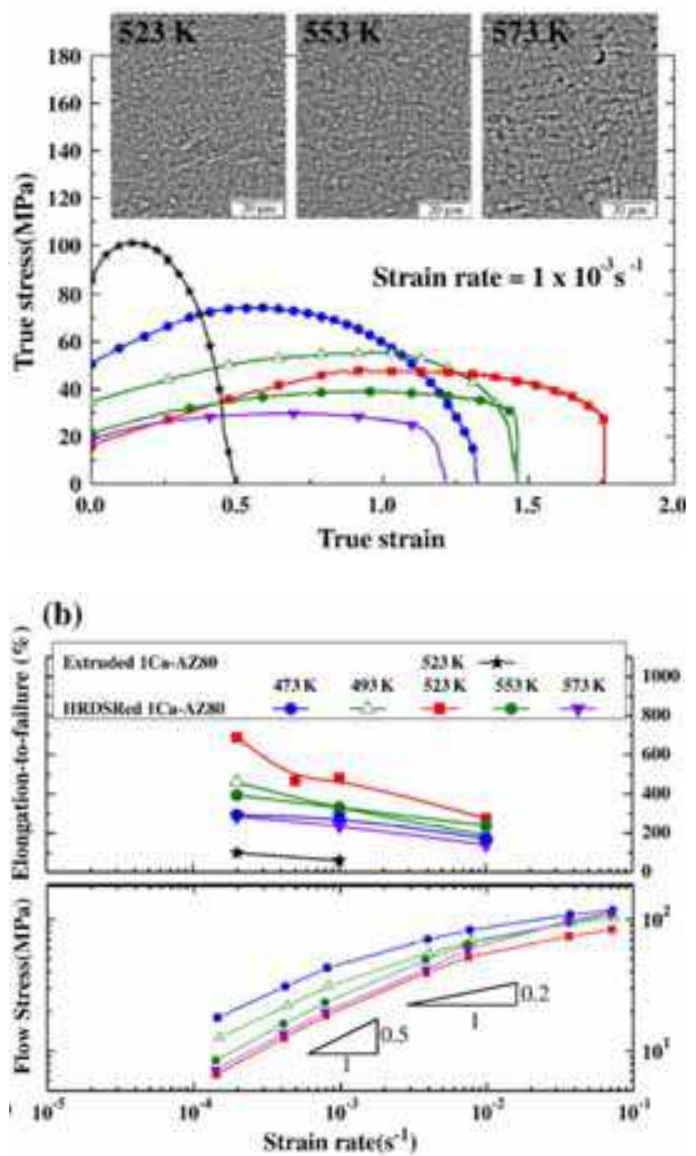

Fig. 15. (a) True stress - true strain curves for the extruded and HRDSRed 1Ca-AZ80 Mg alloy at $1 \times 10^{-3} \mathrm{~s}^{-1}$ at various temperatures. The insert presents the HRDSRed microstructures taken before the tensile loading at the three temperatures. (b) [Top] Tensile elongation of the extruded and HRDSRed alloys as a function of the strain rate at various temperatures [Bottom] The SRC results for the HRDSRed alloy at temperature ranges of 473K-573K.

plastic deformation zone in the fine-grained materials is normally larger than the grain size, a reverse slip of the dislocations during unloading is often impossible so that the accumulation of damage is large during cycling (Suresh et al., 1998) . However, Kim et al. (2005) found that ECAPed AZ31 Mg alloy exhibited a lower crack growth rate and lower fatigue limit than the coarse grained counterpart (see in Fig.16) unlike other UFG materials which have a lower threshold and higher fatigue crack growth rates (Vinogradov et al., 1999; Kim and Choi et al., 2003 ). It seems that enhanced ductility due to grain refinement in the ECAPed AZ31 alloy resulted in increasing crack growth resistance because of its better ability to accommodate plastic strains during cycling. Higo et al. (1981) observed a d-1/2 dependence of crack propagation threshold ( $\left.\Delta K_{\text {th }}\right)$ for copper alloys. Therefore, the 
influence of grain size on the fatigue properties of UFG materials seems to be very complex due to the interaction between several intrinsic and extrinsic factors. Zúberová et al. (2007) also reported that the fatigue lifes of ECAPed AZ31 alloy (average grain size of about 1 to $2 \mu \mathrm{m})$ are superior to that of the squeeze-cast alloy in the low-cycle and high-cycle regions.

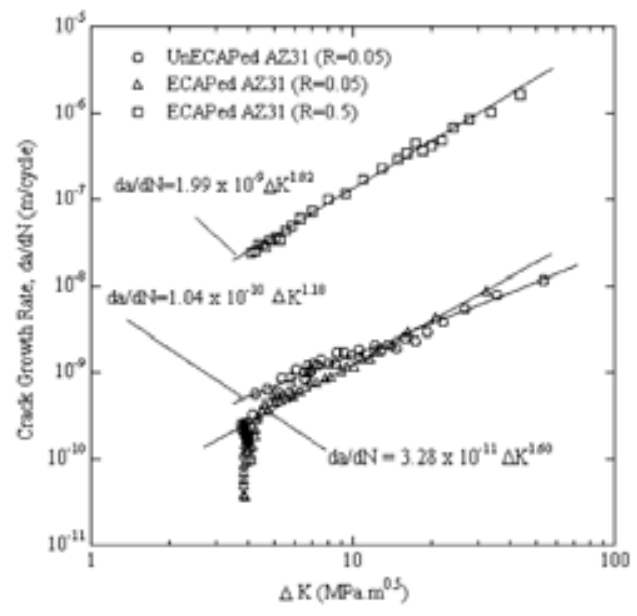

Fig. 16. A comparison of fatigue crack growth behavior of the unECAPed and ECAPed AZ31 alloys.

\subsection{Deformation mechanism of SPD-produced UFG Mg alloys}

The unique mechanical properties of SPD-produced UFG Mg alloys are attributed to their unique deformation mechanisms different from their coarse-grained counterparts. The deformation mechanisms include full dislocation and partial dislocations slip, deformation twinning, wide stacking faults, grain-boundary sliding and grain rotations. The activation and signification of each mechanism depend on intrinsic material properties (such as stacking-fault energy and shear modulus), structural features (such as grain size) and external factors (such as SPD temperature and applied stress). With decreasing grain size, full dislocation slip decreases but partial dislocation emits from grain boundaries become significant (Zhu et al., 2003; Yamakov et al., 2004). A transition from twinning to slip dominated flow is found for grains sizes less than a few micrometers (Zheng et al., 2008). Moreover, GBS and grain rotation may become significant deformation mechanism, leading to abnormal Hall-Petch relationship.

Table 1 summarizes the microscale deformation mechanism that have been inferred or identified in ECAPed Mg alloys. The initial texture had the effect of increasing the non-basal activity. Kim et al (2003) noted a decrease from an initial axisymmetric texture of $7.0 \mathrm{mr}$ (multiply random) in AZ61 Mg alloy to $5.6 \mathrm{mr}$ after first pass and then to $2.8 \mathrm{mr}$ after second pass. Agnew et al.(2005) showed that texture development in ECAPed AZ31 evolved differently depending on their initial extruded texture. Basal, prismatic or some combination of the two are most dominant in the first pass, and pyramidal $\langle\mathrm{c}+\mathrm{a}\rangle$ and twinning are less so. One plausible reason for the common features in the one-pass hcp textures is the predominance of $<\mathrm{a}>$-slip. 


\begin{tabular}{|c|c|c|c|c|c|c|}
\hline \multirow{2}{*}{ Materals } & \multicolumn{4}{|c|}{ ECAP processing } & \multirow{2}{*}{$\begin{array}{l}\text { Deformation } \\
\text { mechanism }\end{array}$} & \multirow{2}{*}{ Reference } \\
\hline & $\mathrm{T} /{ }^{\circ} \mathrm{C}$ & $\Phi / \psi$ & Passes & routes & & \\
\hline AZ31 & 200,300 & $90^{\circ}$ & $1-4$ & A & $\begin{array}{l}\text { basal,prismatic, } \\
\text { pyramidal<c+a> }\end{array}$ & $\begin{array}{l}\text { Agnew et } \\
\text { al., } 2005\end{array}$ \\
\hline ZK60 & $\begin{array}{l}260- \\
325\end{array}$ & $90^{\circ}$ & $1-4$ & A & $\begin{array}{l}\text { basal,prismatic, } \\
\text { pyramidal<c+a> }\end{array}$ & $\begin{array}{l}\text { Agnew et } \\
\text { al., } 2005\end{array}$ \\
\hline WE43 & $\begin{array}{l}260- \\
325\end{array}$ & $90^{\circ}$ & $1-4$ & A & $\begin{array}{l}\text { basal,prismatic, } \\
\text { pyramidal }<\mathrm{c}+\mathrm{a}>\end{array}$ & $\begin{array}{l}\text { Agnew et } \\
\text { al., } 2005\end{array}$ \\
\hline $\mathrm{Mg}-4 \mathrm{Li}$ & 260 & $90^{\circ}$ & $1-4$ & A & basal,prismatic & $\begin{array}{l}\text { Agnew et } \\
\text { al., } 2005\end{array}$ \\
\hline AZ31 & 200 & $90^{\circ} / 37^{\circ}$ & $1^{\text {st }}$ & & $\begin{array}{l}\text { basal,prismatic, } \\
\text { tensiling twinning }\end{array}$ & $\begin{array}{l}\text { Yoshida et } \\
\text { al., } 2003\end{array}$ \\
\hline AZ31 & 250 & $90^{\circ} / 37^{\circ}$ & $1^{\text {st }}$ & & basal,pyramidal $<\mathrm{C}+\mathrm{a}>$ & $\begin{array}{l}\text { Yoshida et } \\
\text { al., } 2003\end{array}$ \\
\hline AZ61 & 275 & $90^{\circ} / 30^{\circ}$ & 8 & Bc & basal,prismatic & $\begin{array}{l}\text { Kim et al., } \\
2003\end{array}$ \\
\hline $\begin{array}{c}\mathrm{Mg}- \\
3.3 \% \mathrm{Li}\end{array}$ & 250 & $90^{\circ}$ & 4 & $\mathrm{Bc}$ & $\begin{array}{l}\text { basal,prismatic, } \\
\text { pyramidal<c+a> }\end{array}$ & $\begin{array}{c}\text { Liu et } \\
\text { al.,2004 }\end{array}$ \\
\hline
\end{tabular}

Table 1. Recent studies on microscale deformation mechanism in ECAPed Mg alloys .

The deformation modes are high dependent on the temperature and alloys. Increasing the temperature can alter the type of deformation mechanism (such as from twinning to slip), the relative activity of these mechanism and the fraction of recrystallized grains. During high-temperature ECAP processing, the differences between the critical resolved shear stresses (CRSS) of the basal slip and those of the nonbasal slip modes are lower. Therefore, it is possible that prismatic and $\langle\mathrm{C}+\mathrm{a}\rangle$ pyramidal modes are activated, in combination with basal slip, producing observable changes in texture evolution after the first pass. a Agnew et al.(2005) found that both initial texture effects and alloying had large effects on texture evolution of various Mg alloys. Two alloys (AZ80 and AZ31) with similar solid-solution Al content but different initial textures had the same texture evolution dominated by basal slip, while Mg-4Li alloy had a different one-pass texture due to the non-basal activity promoted by Li. As shown in Table 1, deformation mechanisms of ECAPed Mg alloys will also be highly dependent on processing routes and passes. Each route has a different "entry" texture that may invoke different deformation modes. With increasing the ECAP pass, twinning will not be favoured over slip due to the combination of grain refinement and high processing temperature. A dislocation process with possibly some fine-scale twinning at grain boundaries must be the primary deformation mechanism at room temperature for UFG Mg alloys.

Due to the low-symmetry crystal structure, a grain in $\mathrm{Mg}$ alloys needs to call up a combination of several possible slip or twinning modes to accommodate deformation. The choice depends heavily on their crystallographic orientation. Unlike cublic materials (fcc and bcc), not every hcp material uses the same set of slip and twinning modes. For the same orientation, one type of hcp crystal would use one or two slip modes, while another type would use a combination of twinning and slip (Beyerlein \& Tóth, 2009). Zheng et al.(2008) found that the compressive stress-strain curve of an ECAPed Mg-Zn-Y-Zr alloy includes a short region with high strain hardening rate, followed by a long steady state region with 
very low strain hardening rate (see Fig.17a). The grain size is significantly refined and the basal planes are inclined about $45^{\circ}$ to the extrusion direction. These effects may impede the activation of $\{10 \overline{1} 2\}$ twinning in compression. The reduced grain size may be the most important cause for the suppression of twinning, because the twinning stress increases with decreasing grain size. Fig. 17(b) shows a typical microstructure of the ECAPed Mg alloys after a compressive true strain of 0.6 at a strain rate of $1.67 \times 10^{-3} \mathrm{~s}^{-1}$ at $423 \mathrm{~K}$. No visible twins indicated that at lower strains, plastic flow is dominated by dislocation motion. The suppression of twinning may also result in low strain hardening. In addition, the UFG structure of the ECAPed alloy is scarcely modified after compression to higher strains. This may be due to the restriction of grain growth by the dispersion of fine I-phase (quasicrystalline icosahedral phase) and precipitates in the alloy. The enhanced strain rate sensitivity, low strain hardening rate of the ECAPed alloy together with the microstructures after compression indicate that different deformation mechanisms are active in the UFG ECAP-processed and as-extruded alloy. They may include thermally activated climbcontrolled annihilation of lattice dislocations in or near grain boundaries (May et al., 2005) as well as GBS and Coble creep.

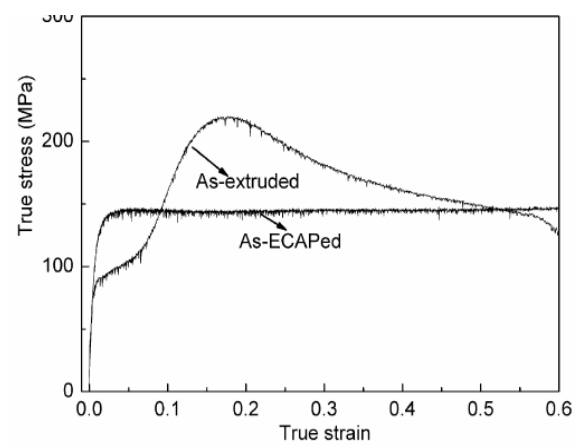

(a)

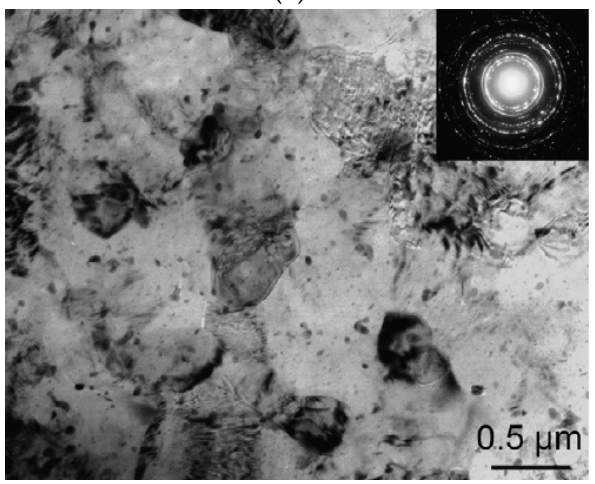

(b)

Fig. 17. (a) Compressive true stress-true strain curves at a strain rate of $1.67 \times 10^{-3} \mathrm{~s}^{-1}$ at $423 \mathrm{~K}$ for the ECAPed and extruded Mg-Zn-Y-Zr alloys. (b) Microstructure of the ECAPed alloy after compression (The insert presents the diffraction pattern taken with a $9 \mu \mathrm{m}$ aperture). 
Special mention should be made of GBS as another possible deformation mechanism in UFG $\mathrm{Mg}$ alloys. When the grain size is very small, GBS has been predicted to be a deformation mechanism by MD simulations (Meyers et al.,2006). This mechanism was reported in pure $\mathrm{Mg}$ with a fairly large grain size of about $1 \mathrm{~mm}$ at room temperature by Hauser et al. in 1956. Later, Gifkins and Langdon (1964) analyzed the possibility of GBS at room temperature in $\mathrm{Mg}$ and $\mathrm{Mg}$ alloys with grain sizes of $100-300 \mu \mathrm{m}$. They claimed that GBS does not occur at room temperature and that the step formation was due to different amounts of shear localized in neighboring grains. In contrast, Koike et al.(2003) have recently reported the occurrence of GBS at room temperature in $d=8 \mu \mathrm{m}$ AZ31 alloy, and determined the strain contribution by measuring the displacements of marked lines at the surface. The ratio of GBS strain to total strain was estimated to be near to $8 \%$. Kim et al. (2009) also observed deviations from the Hall-Petch relationship in Mg-Li alloy with a grain size of $1 \mu \mathrm{m}$ and proposed the negative slope observed in the Hall-Petch plot is related to transition from pipe diffusion -controlled slip creep to grain boundary diffusion-controlled GBS. The critical grain size associated with abnormal Hall-Petch behavior is predicted to vary depending on the strain rate and diffusivity.

\section{Corrosion resistance of SPD-processed $\mathrm{Mg}$ and Mg alloys}

Grain refinement is proved to be favorable to improving mechanical properties of pure $\mathrm{Mg}$ and its alloys, but the precise effect of grain size on corrosion at a fundamental level is not widely understood. There is only limited attention that is focused on electrochemical properties of SPDed Mg and its alloys. As well known, the standard electrode potential of $\mathrm{Mg}\left(-2.37 \mathrm{~V}_{\mathrm{NHE}}\right)$ is the lowest among metallic elements, and thus $\mathrm{Mg}$ and its alloys have poor corrosion resistance in comparison with other conventional metallic structural materials. This shortcoming limited their industrial applications (Jönsson et al.,2007; Ambat et al., 2000), therefore particular attention should be paid to corrosion resistance improvement of $\mathrm{Mg}$ and its alloys in aggressive environments (e.g. $\mathrm{Cl}^{-}$-containing aqueous media). Their low corrosion resistance in aqueous media are mainly related to high permeability and low stability of $\mathrm{Mg}$ hydroxide film (Nordlien et al., 1997), and high sensitivity of $\mathrm{Mg}$ to impurities and alloying elements that promote internal galvanic attacks (Volovitch et al., 2009) . Recent related work in the authors' group has shown that the corrosion rate of ECAPed pure $\mathrm{Mg}$ was increased in $\mathrm{NaCl}$ aqueous solution but UFG ZE41A alloy by ECAP had slower corrosion rates compared to coarse grained one ( Song et al., 2010; Jiang et al., 2009). The outcomes of such work indicated that grain refinement by SPD, in some cases, was beneficial to reduced corrosion resistance. The provenience of a particular grain structure is of crucial importance and that there are factors other than the grain size that control corrosion response. Herein, the corrosion of SPDed Mg and its alloys are focused in order to address a critical fundamental knowledge gap in the assessment of $\mathrm{Mg}$ corrosion as a function of grain size and grain character.

\subsection{Corrosion characteristics of UFG pure Mg}

Recently, the potential effect of grain size on corrosion of pure Mg was investigated by processing the UFG specimens using ECAP and surface mechanical attrition treatment (Birbilis et al., 2010; Song et al., 2010). Some relevant prior works indicated that significant variation in corrosion rate depend on decreasing grain size when used individual mechanical processing techniques, while no clear trend in the dependence of corrosion properties on the grain size when examined independently of mechanical processing. 
Song et al.(2010) found that the ECAPed pure Mg after 6 passes at 573K, compared with ascast one $(800 \sim 1500 \mu \mathrm{m})$, obtained finer grains $(50 \sim 100 \mu \mathrm{m})$ but was fined slightly with further pressing. The strain-induced grain refinement with more crystalline defects weakened corrosion resistance of pure $\mathrm{Mg}$, resulting in more and deeper pits after in-situ corrosion, higher mass-loss rate immersed in $\mathrm{NaCl}$ solution, larger Icorr values in polarization curves and lower fitted Rt values in EIS plots. However, the enhanced initial open-circuit-potential (OCP) values indicate better weather resistance. Furthermore, corrosion improvement can be expected by reducing defects via subsequent annealing.

Op'tHoog et al.(2008) investigated corrosion behaviors of pure $\mathrm{Mg}$ produced by a variety of mechanical or thermo-mechanical processes and annealed at $250{ }^{\circ} \mathrm{C}$. Fig. 18 presents the average grain sizes as a function of annealing time and corrosion current versus grain size for pure $\mathrm{Mg}$. For the cast specimens, a weak linear decrease in corrosion current with decreasing grain size was found. SMAT process is believed to induce an extremely high free energy state in the near-surface region, resulting in an increased corrosion current response despite decreasing grain size. Overall, the ECAPed specimens exhibit better corrosion

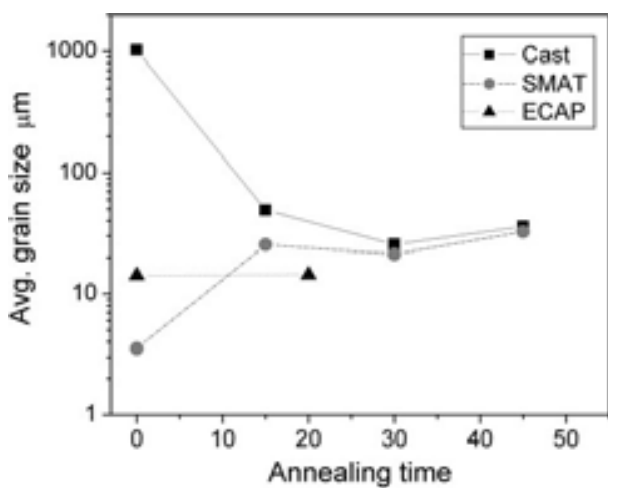

(a)

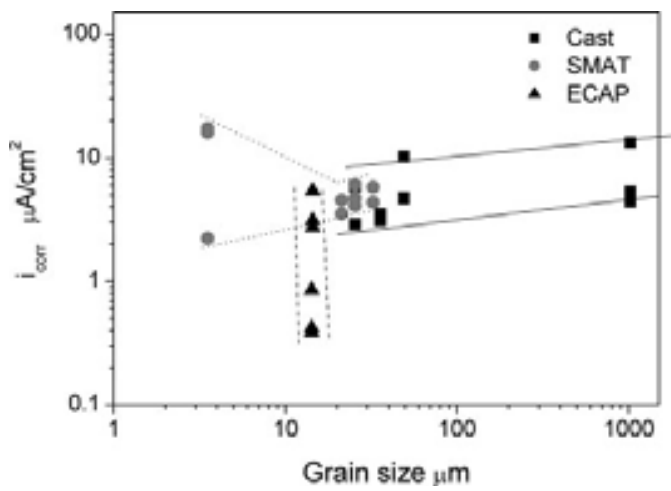

(b)

Fig. 18. (a) Average grain sizes as a function of annealing time for pure $\mathrm{Mg}$ (in minutues). (b) Corrosion current versus grain size for pure $\mathrm{Mg}$ (Data sets have been grouped according to processing method). (Op'tHoog et al. 2008) 
resistance with notably lower values of $i$ corr, compared with that of the SMATed and as-cast specimens. The distinct difference in corrosion behavior strongly indicated that grain size may not be the only factor in tailoring corrosion properties through thermo-mechanical processing. Recently, A hypothesis was given that the increased density of grain boundaries with high misorientation, formed during continued ECAP processing, can promote a more coherent oxide (Birbilis et al.,2010).

The natural oxide layer of $\mathrm{Mg}$ is not stable in aqueous solutions (below about $\mathrm{pH} 11$ ) and easily crack owing to high compression stresses within the oxide layer (geometrical mismatch with respect to the hexagonal Mg lattice) (Kainer et al, 2003). By deliberately introducing a large volume fraction of grain boundaries in the bulk material, the mismatch may be diminished with the development of a more coherent, uniform and protective file on Mg surface. Potentiodynamic polarisation data (Op'tHoog et al., 2008), collected upon Mg specimens in various conditions, suggested that ECAP treatment simultaneously lower the anodic and cathodic kinetics, thus improving the surface oxide quality by modifying the substrate structure of Mg. For SMATed specimens, the surface film quality is not improved due to increased LAGB density via a peening mechanism and massive residual stresses. Recent studies suggest that major residual stresses are detrimental to electrochemical behavior (Uhlenhaut et al., 2009).

We would like to emphasise that there is a lack of literature on purely microstructural effects on corrosion of SPDed $\mathrm{Mg}$, particularly in the absence of alloying elements. If the grain structure is varied with isolated effects of chemistry, the potential effect of grain size on corrosion could be determined. General speaking, electrochemical response of $\mathrm{Mg}$ can be controlled through microstructural variations via SPD procedures. For improving corrosion resistance of pure $\mathrm{Mg}$, the provenience of a particular UFG structure is of crucial importance. And the high fraction of HAGB and the low residual stress (surface free energy) in UFG Mg can also be expected, which depends sensitively on the SPD processing.

\subsection{Corrosion behaviors of UFG Mg alloys}

UFG Mg alloys processed by SPD method are potentially attractive since they exhibit higher strength and better ductility in comparison with their coarse-grained counterparts. However, electrochemical properties of SPDed materials have received only limited attention and the effect of grain size on corrosion behavior of UFG Mg alloys is not widely understood. Alloying elements and its distribution have also great effect on electrochemical responses of UFG Mg alloys. Therefore, particular attention should be paid to the relationship between corrosion behavior and microstructure changes of UFG SPDed Mg alloys with various alloying elements to meet the needs of structural applications.

Hamu et al. (2009) investiged the relation between microstructure and corrosion behavior of ECAPed AZ31 Mg alloy for 4 passes at $350^{\circ} \mathrm{C}$. All the electrochemical measurements were performed in $3.5 \% \mathrm{NaCl}$ saturated with $\mathrm{Mg}(\mathrm{OH})_{2}$ with a $\mathrm{pH} 10.5$, at which $\mathrm{Mg}$ can cover itself with more or less protective oxide or hydroxide which inhibits the dissolution reaction. After initial ECAP passes, the "bimodal" microstructure with coarse grains surrounded by fine ones was observed. The grain structure, however, became visibly uniform with further ECAP deformation. The average grain size was considerably reduced from over $30 \mu \mathrm{m}$ (asreceived) to below $10 \mu \mathrm{m}$. Clearly, processing at a temperature well above $0.5 \mathrm{Tm}$ was more effective and this might be attributed to the suppression of DRX and grain growth. TEM observation showed that the density of the dislocations in the ECAPed alloys (extrusion 
ratio $98.99 \%$ ) increases significantly around small second phases (average size of $150 \mathrm{~nm}$ ) and grain boundaries, and there apparently existed lots of twins (see Fig.19). Although the grain size after ECAP process was similar to the grain size after conventional extrusion (extrusion ratio 91.34\%), a sharp increase in the corrosion rate and relatively less noble behavior for the ECAPed AZ31 are caused due to a higher density of dislocation and twins, i.e relatively higher deformation energy. The corrosion resistance of AZ31 $\mathrm{Mg}$ alloys following conventional extrusion was increased due to smaller grain size in comparison to that as received one (see Fig.20). Therefore, once fully recrystallized structured are formed with increasing the pass number of ECAP, the electrochemical potential of the $\mathrm{Mg}$ matrix may be nobler with decreasing the anodic dissolution due to the lower dislocation density.
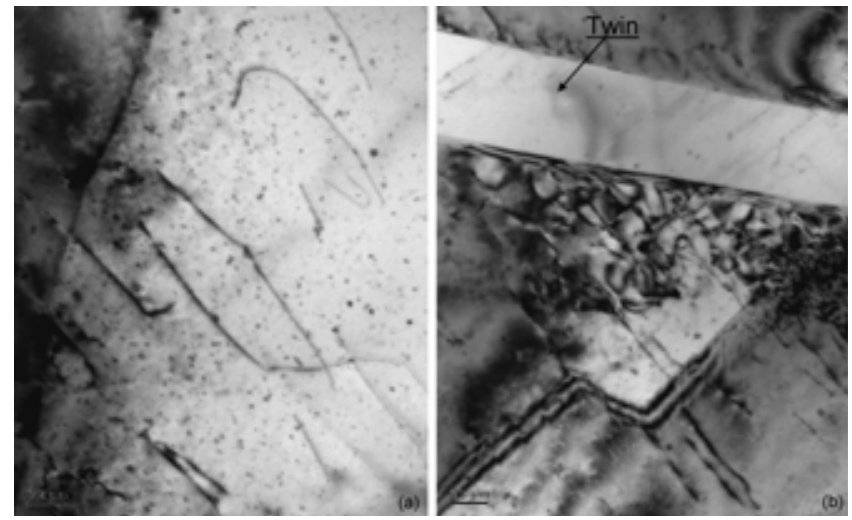

Fig. 19. Typical microstructures of the ECAPed AZ31 alloy for 4 passes at $350^{\circ} \mathrm{C}$ (extrusion ratio 98.99\%). (a) dislocation arrangements; (b) structure of the twins. (Hamu et al., 2009)

Our recent studies proved that significant grain refinement has beneficial effect on corrosion resistance of ZE41A Mg alloy through a large number of ECAP passes (Jiang et al., 2009). After ECAP over 16 passes at $603 \mathrm{~K}$, ultrafine equiaxial grains (about $2.5 \mu \mathrm{m}$ ) were obtained with homogeneously dispersed fine secondary particles (about $5-8 \mu \mathrm{m}$ ) due to plasticinduced grain refinement accommodated by DRX. The ECAPed sample had lower corrosion susceptibility with increasing ECAP passes ( see Fig.21). The lower corrosion current density and nobler corrosion potential correlated with large number of pressing passes were attributed to the low tendency toward localized corrosion after homogenization of broken secondary phase on ultra-fine grained Mg matrix. Fig.22 exhibits SEM micrographs of the corroded surface of ECAPed ZE41A alloy immersed in $35 \mathrm{~g} / \mathrm{L} \mathrm{NaCl}$ for 30min. Obviously, there are micro-crackings on the corroded surface of the 8-, 16-, and 32-pass samples, probably due to the presence of residual internal stress. The 60P-passes sample appears to be more resistant to corrosive attack, because the complete DRX of the deformed microstructure reduces the tendency toward stress corrosion cracking and pitting. It is well known that DRX decreases the residual internal stress and intragranular dislocation density of the deformed microstructure and leads to the presence of higher fraction of HAGB. The residual internal stress in ECAPed sample is adverse to partial protective layer adhered on $\mathrm{Mg}$ matrix, therefore it should be eliminated as complete as possible. It means that the percentage of DRX has great effect on corrosion resistance of UFG ZE41A alloy with fine and homogeneous secondary particles. 


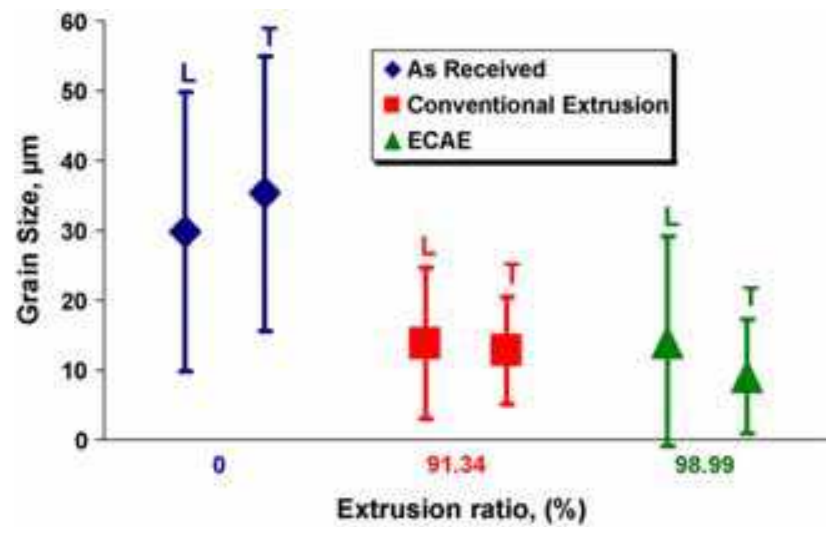

(a)

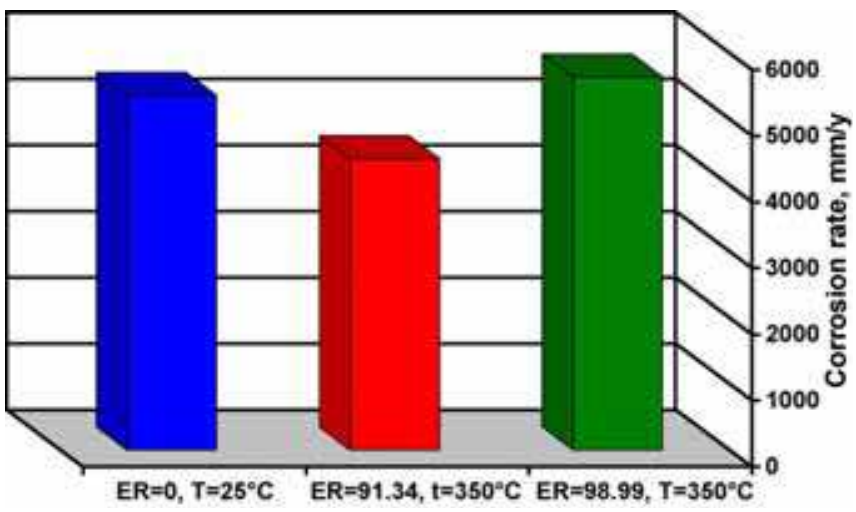

(b)

Fig. 20. Variation in grain size (a) and corrosion rate (b) of AZ31 Mg alloy in different extrusion ratios(ER). (Hamu et al. , 2009) 


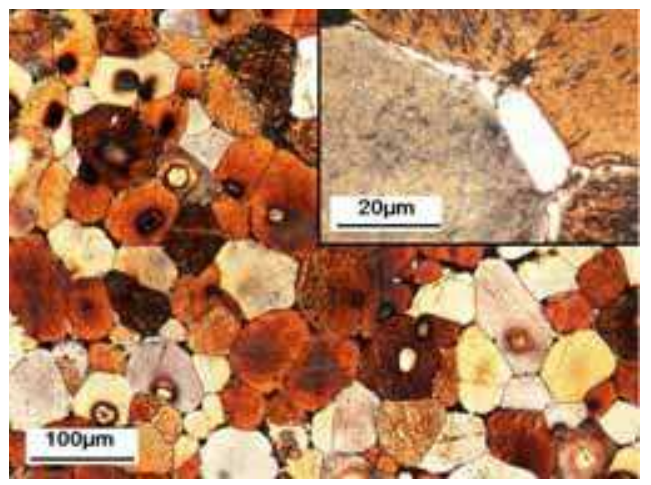

(a)

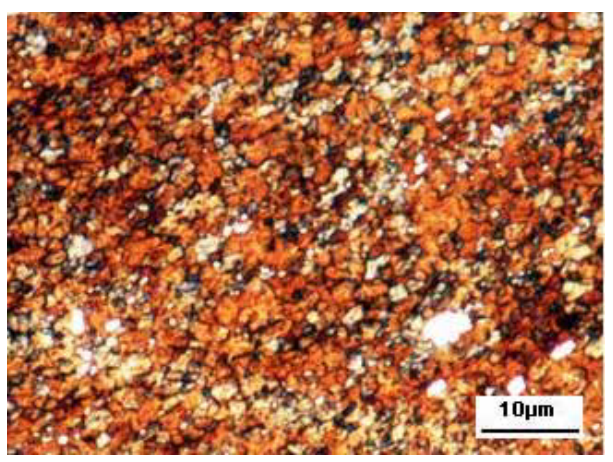

(b)

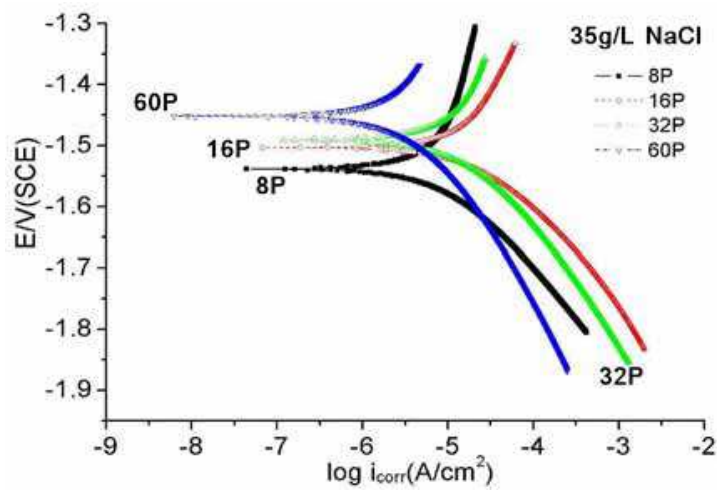

(c)

Fig. 21. Micrographs and potentiostatic polarization curve of ZE41A Mg alloy. Optical microstructure for (a) as-received one and (b) after 32 passes ECAP; (c) polarization curve of ECAPed alloy in $35 \mathrm{~g} / \mathrm{L} \mathrm{NaCl}$ aqueous solution. 

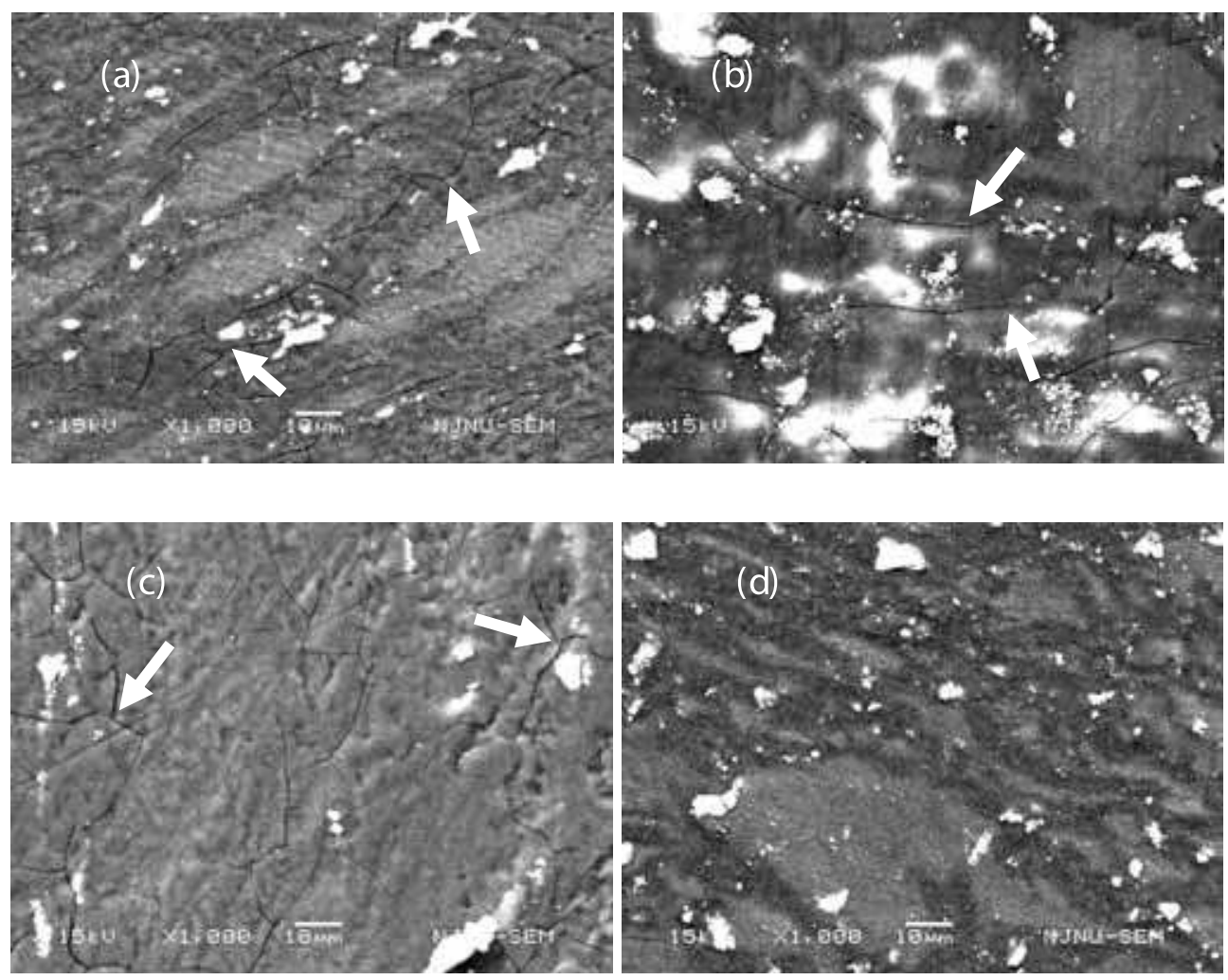

Fig. 22. SEM surface morphologies of the ECAPed ZE41A with various passes after $30 \mathrm{~min}$ immersion in 35g/L NaCl solution: (a) 8passes, (b)16passes,(c)32passes, and (d) 60passes.

In general, ECAP is effective in improving the corrosion resistance of Mg-based alloy. Large number of ECAP pass within the temperature range of DRX is necessary to obtain UFG structure with low dislocation density and residual internal stress, thus leading to low anodic dissolution. Otherwise, internal galvanic corrosion attack on $\mathrm{Mg}$ alloy is strongly influenced by the distribution and morphology of secondary phases. The enhanced corrosion resistance of UFG ZE41A Mg alloy proves that enough passes of ECAP within the temperature range of DRX can endow UFG bulk alloy with higher resistance to electrochemical attack besides exceptional mechanical advantages. It means that fabricating UFG materials by SPD method can be developed a new strategy for improving the comprehensive properties of structural materials. The UFG Mg alloy processed by ECAP method is attractive for some potential applications.

\subsection{Criteria for optimizing the corrosion resistance}

Based on the fundamental aspects of the corrosion behaviours of SPDed Mg alloys, attempts to enhance the corrosion resistance of UFG Mg-based materials must therefore aim at enhancing the homogenization and stability of UFG microstructures, reducing residual stress and dislocation density, and at the same time, improving the corrosion prevention of 
the natural passivated layer on $\mathrm{Mg}$ substrate. In detail, the following points are considered to play an important role:

a. Stability and homogenization of UFG microstructure.

Although a fundamental knowledge of corrosion behaviour varied with the individual microstructures of Mg alloy is still lacking, recent studies present that UFG microstructure with high fraction of HAGB, low residual stress and intragranular dislocation density is advantageous to the electrochemical behaviour. In order to achieve the optimum corrosion resistance, the fully recrystallized structure without grain growth is expected during SPD. The microstructure stability is strongly affected by SPD process parameters, in particular by the route and pass number of ECAP and the amount and the kind of impurities of the $\mathrm{Mg}$ alloys used. Uniform distribution of fine secondary particles may inhibit significant grain growth of the matrix phases of Mg alloys SPD-processed at the temperature range of DRX and reduce the tendency toward localized corrosion, thus resulting in relatively high corrosion resistance. It means that suitable annealing treatments have a positive effect on the corrosion behaviour of UFG Mg alloy after initial passes ECAP, while a large number of ECAP can enhance the corrosion resistance due to a complete recrystallization of the UFG microstructure. Introducing fine and homogeneous secondary particles is crucially important to inhibit the grain growth during SPD, resulting in the formation of UFG microstructure with low residual stress and high fraction of HAGB.

b. Production of stable protective layer

In moist air, $\mathrm{Mg}$-based materials naturally tend to form a thin passivated layer, which consists mainly of $\mathrm{Mg}(\mathrm{OH})_{2}$ and hydrated oxide components of alloying elements. Judged by the Pilling-Bedworth ratio, the natural passivated layer on $\mathrm{Mg}$ alloy is no dense and cannot protect the metal in the long term due to geometric mismatching. However, satisfactory surface protective layer is capable to be formed on the UFG Mg containing alloying elements such as $\mathrm{Al}, \mathrm{Zn}$ and rare earth. These elements exercise a positive influence on the corrosion stability of the surface of $\mathrm{Mg}$, which effect on corrosion response of SPDed $\mathrm{Mg}$ should be throughly investigated. Recent studies present that the improved corrosion resistance seems to arise from rapid formation of passive films due to an increase in grain boundaries and dislocations in the UFG materials, but no impurities segregated to grain boundaries.

\section{Summary and outlook}

Several new trends in SPD processing for fabrication of bulk ultrafine-grained Mg alloys have been presented in this chapter, based on recent results in a global world. Presently new tasks, connected with economically feasible production of UFG Mg alloys, started to be solved through decreasing the material waste, obtaining homogeneous structure and advanced properties in bulk billets and products. Although ECAP is an effective route to UFG billets by imparting large shear strains, the conventional process has some limitations for commercialization. Studies focused on continued ECAP technique of bulk UFG Mg alloys, as well as their structural features and potential for obtaining extraordinary properties, are of special interest.

Because of their small grain sizes, UFG Mg alloys after SPD processing exhibit high strength and ductility, superplasticity, enhanced corrosion resistance, and other attractive properties. Microstructure characteristic and principal properties of bulk UFG Mg alloys processed by 
various SPD procedures are briefly surveyed, with emphasis on their mechanical properties and corrosion behaviour after ECAP procedure. Our focus is on the effect of the grain size on intrinsic mechanical and corrosion response of UFG Mg alloys, without paying detailed attention to subtle microstructural differences in these materials. It appears that more systemic studies are needed to tailor the ECAP-processing conditions for obtaining microstructures favourably affecting mechanical properties and corrosion resistance. To obtain the benefit of the high strength and good ductility of UFG Mg alloy, a through understanding of their deformation models is imperative but also challenging. Despite years of research, a consensus on the deformation mechanism of UFG Mg alloy processed by SPD has not yet been reached. Partial dislocation emission from grain boundaries and grainboundary sliding may become significant deformation mechanism with decreasing grain size, resulting in significantly increasing ductility and strength. As concerns the corrosion resistance of UFG Mg, these seem to be also enhanced in comparison to their coarse-grained counterparts, although the extent of the improvement clearly depends on the processing methods. The interior dislocation and HAGB densities in UFG Mg alloy play an important role in oxide formation and corrosion susceptibility, which potential effect on corrosion should be determined. Anyway, fabricating UFG materials by SPD method can be developed a new strategy for improving the comprehensive properties of structural Mgbased materials, which are attractive for some potential, marketable applications.

\section{References}

Agnew, S.; Horton, J.; Lillo, T. \& Brown. D. (2004) Enhanced ductility in strongly textured Mg produced by equal channel angular processing. Scripta Mater., Vol. 50, (Febr. 2004) Pages 377-381, ISSN: 1359-6462.

a Agnew, S.; Mehrotra, P.; Lillo, T.; Stoica, G. \& Liaw, P. (2005). Texture evolution of five wrought $\mathrm{Mg}$ alloys during route A equal channel angular extrusion: Experiments and simulations. Acta Mater., Vol. 53, (June 2005) Pages 3135-3146, ISSN: 1359-6454.

b Agnew, S.; Mehrotra, P.; Lillo, T.; Stoica, G. \& Liaw, P. (2005) Crystallographic texture evolution of three wrought $\mathrm{Mg}$ alloys during equal channel angular extrusion. Mater. Sci. Eng. A, Vol. 408, (Nov. 2005) pages 72-78, ISSN: 0921-5093.

Alkorta, J.; Rombouts, M.; Messemaeker, J. ; Froyen, L. \& Sevillano J. (2002). On the impossibility of multi-pass equal-channel angular drawing. Scripta Mater., Vol. 47, (July 2002) Pages 13-18, ISSN:1359-6462.

Ambat, R.; Aung, N. \& Zhou, W. (2000). Evaluation of microstructural effects on corrosion behaviour of AZ91D Mg alloy. Corros. Sci., Vol.42 , (August 2000) Pages 1433-1455, ISSN:0010-938X.

Avedesian, M. \& Baker, H. (1999). Mg and Mg Alloys, ASM International, ISBN: 0-87170-6571,USA.

Azushima, A.; Aoki, K.; Asada, Y. \& Kimura, Y. (2002). High strengthening by combination process of shear deformation and rolling. Proceedings of 2002 Japanese Spring Conference on Technology of Plasticity, pp.309-310, ISBN:0919-1925, Chiba, May 2002, JSTP, Tokyo (in Japanese).

Azushima, A.; Kopp, R.; Korhonen, A.; Yang, D.; Micari, F.; Lahoti, G.; Groche, P.; Yanagimoto, J. ; Tsuji, N.; Rosochowski, A. \& Yanagida, A. (2008). Severe plastic 
deformation (SPD) processes for metals. CIRP Annals - Manufacturing Technology, Vol.57, (Oct. 2008) Pages 716-735, ISSN: 0007-8506.

Berbon, B.; Furukawa, M.; Horita, Z.; Nemoto, M. \& Langdon, T. (1999). Influence of pressing speed on microstructural development in equal-channel angular pressing. Metall. Mater. Trans., Vol.30, No.8, (Aug. 1999) Pages 1989-1997, ISSN: 1073-5623.

Beyerlein, I. \& Tóth, L. (2009) Texture evolution in equal-channel angular extrusion. Prog. Mater .Sci., Vol.54, (June. 2009) Pages 427-510, ISSN: 0079-6425.

Birbilis, N.; Ralston, K.; Virtanen, S.; Fraser, H. \& Davies, C. (2010) Grain character influences on corrosion of ECAPed pure magnesium. Corros. Eng. Sci. Techn.,Vol.45, (June 2010) Pages 224-230, ISSN:1478-422X

Bridgman, P. (1935) Effects of High Shearing Stress Combined with High Hydrostatic Pressure. Physical Review, Vol.48, (Nov. 1935) Pages 825-847.

Chang, C.; Wang, Y.; Pei, H.; Lee, C. \& Huang, J. (2006) On the Hardening of Friction Stir Processed Mg-AZ31 Based Composites with 5-20\% Nano-ZrO2 and Nano-SiO2 Particles. Mater. Trans. , Vol.47, (Dec. 2006) Pages 2942-2949,. ISSN: 1345-9678.

Chang, T. ; Wang, J. ; Chu, C. \& Lee, S. (2006). Mechanical properties and microstructures of various Mg-Li alloys. Mater. Letters. Vol.60, (Nov. 2006) Pages 3272-32763. ISSN: 0167-577X

Cheng, Y.; Chen, Z. \& Xia, W. (2007). Effect of crystal orientation on the ductility in AZ31 $\mathrm{Mg}$ alloy sheets produced by equal channel angular rolling. J. Mater. Sci. , Vol.42, (May 2007) Pages 3552-3556, ISSN: 0022-2461.

Chuvil'deev, V.; Nieh, T.; Gryaznov, M.; Sysoev, A. \& Kopylov, V. (2004) Low-temperature superplasticity and internal friction in microcrystalline $\mathrm{Mg}$ alloy processed by ECAP. Scripta Mater., Vol.50, (March 2004) Pages 861-865, ISSN:1359-6462.

Del Valle, J.; Pérez-Prado M. \& Ruano, O. (2005). Accumulative roll bonding of a Mg-based AZ61 alloy. Mater. Sci. Eng. A , Vol. 410-411, (Nov. 2005) Pages 353-357, ISSN: 09215093

Del Valle, J.; Carreno, F. \& Ruano, O. (2006). Influence of texture and grain size on work hardening and ductility in Mg-based alloys processed by ECAP and rolling. Acta Mater., Vol.54 , (Sept. 2006) Pages 4247-4259, ISSN:1359-6454.

Ferrase, S.; Segal, V.; Kalidindi, S. \& Alford, F. (2004). Texture evolution during equal channel angular extrusion: Part I. Effect of route, number of passes and initial texture. Mater. Sci. Eng. A, Vol. 368 ( March 2004) Pages 28-40, ISSN: 0921-5093.

Figueiredo, R. \& Langdon, T. (2006) . The development of superplastic ductilities and microstructural homogeneity in a Mg ZK60 alloy processed by ECAP. Mater. Sci. Eng. A. Vol.430, (Aug. 2006) Pages 151-156, ISSN: 0921-5093.

Furukawa, M.; Iwahashi, Y.; Horita, Z.; Nemoto, M. \& Langdon, T. (1998) The shearing characteristics associated with equal-channel angular pressing. Mater. Sci. Eng. A, Vol. 257, (Dec. 1998) Pages 328-332, ISSN: 0921-5093.

a Furukawa, M.; Horita, Z.; Nemoto, M. \& Langdon, T. (2001) Review: Processing of Metals by Equal-channel Angular Pressing. Journal of Material Science, Vol.36, No.12, (June 2001) Pages 2835-2843, ISSN: 0022-2461.

b Furukawa, M.; Utsonomiya, A.; Matsubara, K.; Horita, Z. \& Langdon, T. (2001) Influence of $\mathrm{Mg}$ on grain refinement and ductility in a dilute Al-Sc alloy. Acta Mater., Vol.49, (Oct. 2001) Pages 3829-3838, ISSN: 1359-6454. 
Gan, W. ; Zheng, M. ; Chang, H.; Wang, X.; Qiao, X.; Wu, K.; Schwebke, B. \& Brokmeier H. (2009). Microstructure and tensile property of the ECAPed pure Mg. J. Alloys Compd, Vol.470, (Feb. 2009) Pages 256-262, ISSN: 0925-8388.

Gifkins, R. \& Langdon, T. (1964). On the question of low temperature sliding at grain boundaries. J. Inst. Metals , Vol .93 , Pages 347-352

Raab, G.; Valiev, R.; Lowe, T. \& Zhu, Y. (2004). Continuous Processing of Ultrafine Grained Al by ECAP-Conform. Mater. Sci. Eng. A , Vol.382, (Sept. 2004) Pages 30-34, ISSN: 0921-5093.

Hamu, G.; Eliezer, D. \& Wagner, L. (2009) The relation between severe plastic deformation microstructure and corrosion behavior of AZ31 Mg alloy. J. Alloys Compd, Vol.468, (Jan. 2009) Pages 222-229, ISSN: 0925-8388.

Han, J.; Oh, K. \& Lee J. (2004) Effect of accumulative strain on texture evolution in $1050 \mathrm{Al}$ alloys processed by continuous confined strip shearing. Mater. Sci. Eng. A, Vol.387389, (Dec. 2004) Pages 240-243, ISSN: 0921-5093.

Hauser, F. , Landon, P. \& Dorn, J. (1956). Deformation and fracture mechanisms of polycrystalline $\mathrm{Mg}$ at low temperatures. Trans. Am. Soc. Metals, Vol.48, (Oct. 1956) Pages 986-1002.

Higo, Y.; Pikard, A. \& Knott, J. (1981). Effects of grain size and stacking fault energy on fatigue-crack-propagation thresholds in $\mathrm{Cu}-\mathrm{Al}$ aluminium alloys. Met. Sci ., Vol.15, (June 1981) Pages 233-240, ISSN: 0306-3453.

Huang, J.; Zhu, Y.; Jiang, H. \& Lowe, T. (2001) Microstructures and dislocation configurations in nanostructured $\mathrm{Cu}$ processed by repetitive corrugation and straightening. Acta Mater., Vol.49, (May 2001) Pages1497-1505. ISSN: 1359-6454.

Huang, Y. \& Prangnell, P. (2007) Continuous frictional angular extrusion and its application in the production of ultrafine-grained sheet metals. Scripta Mater. , Vol.56, (March 2007) Pages 333-336, ISSN:1359-6462

Iwahashi, Y.; Wang, J.; Horita, Z.; Nemoto, M. \& Langdon, T. (1996) Principle of equalchannel angular pressing for the processing of ultra-fine grained materials. Scripta Mater., Vol.35 , (July 1996) Pages 143-146, ISSN: 1359-6462.

Jiang,J.; Ma, A.; Saito, N.; Shen, Z.; Song, D.; Lu, F.; Nishida, Y.; Yang, D. \& Lin, P. (2009) Improving corrosion resistance of RE-containing magnesium alloy ZE41A through ECAP. Journal of Rare Earths, Vol.27, (Oct. 2009) Pages 848-852, ISSN: 1002-0721.

Jin, L.; Lin, D.; Mao, D. ; Zeng, X.; Chen, B. \& Ding, W. (2006). Microstructure evolution of AZ31 Mg alloy during equal channel angular extrusion. Mater. Sci. Eng. A , Vol.423, (May 2006) Pages 247- 252 , ISSN: 0921-5093.

Jones, H. \& Lavernia, E. (1998) in: Elements of Rapid Solidification: Fundamentals and Applications.. Otooni, M. A. (Ed.), Page 135, Springer, ISBN: 3540617914, Berlin

Jönsson, M.; Persson \& D.; Thierry, D.(2007) Corrosion product formation during $\mathrm{NaCl}$ induced atmospheric corrosion of Mg alloy AZ91D. Corros. Sci., Vol. 49 (March 2007) Pages 1540-1558, ISSN: 0010-938X.

Kainer, K. (2003) Mg Alloys and Technol. Wiley-VCH, ISBN: 9783527602049, Germany

Kim, W.; Hong, S.; Kim, Y.; Min, S. ; Jeong, H. \& Lee, J.(2003) Texture development and its effect on mechanical properties of an AZ61 Mg alloy fabricated by equal channel angular pressing. Acta Mater., Vol.51 ,(June 2003) Pages 3293-3307, ISSN: 1359-6454. 
Kim, H.; Choi, M. ; Chung, C. \& Shin, D. (2003) Fatigue properties of ultrafine grained low carbon steel produced by equal channel angular pressing. Mater Sci Eng A, Vol.340, (Jan. 2003) Pages 243-250 , ISSN: 0921-5093.

Kim, H.; Lee, Y. \& Chung, C. (2005) Fatigue properties of a fine-grained magnesium alloy produced by equal channel angular pressing. Scripta Mater., Vol.52, (June 2005) Pages 473-477, ISSN: 1359-6462.

Kim, W.; Lee, J.; Kim, W. , Jeong, H. \& Jeong, H. (2007) Microstructure and mechanical properties of $\mathrm{Mg}-\mathrm{Al}-\mathrm{Zn}$ alloy sheets severely deformed by asymmetrical rolling. Scripta Mater., Vol.56, (Febr. 2007) Pages 309-312, ISSN: 1359-6462.

Kim, W.; Yoo, S.; Chen, Z. \& Jeong, H. (2009) Grain size and texture control of Mg-3Al-1Zn alloy sheet using a combination of equal-channel angular rolling and high-speedratio differential speed-rolling processes. Scripta Mater, Vol.60, (May 2009) Pages 897-900, ISSN: 1359-6462.

Kim, W. (2009) Explanation for deviations from the Hall- Petch Relation based on the creep behavior of an ultrafine-grained $\mathrm{Mg}$ - Li alloy with low diffusivity. Scripta Mater, Vol.61, (Sept. 2009) 652-655, ISSN: 1359-6462.

Kim, W. \& Lee, Y. (2010) Enhanced superplasticity of 1 wt.\%Ca-AZ80 Mg alloy with ultrafine grains. Materials letters, Vol. 64, (Aug. 2010) Pages 1759-1762, ISSN: 0167$577 X$.

Ko, Y.; Shin, D. ; Park, K. \& Lee, C. (2006) An analysis of the strain hardening behavior of ultra-fine grain pure titanium. Scripta Mater. Vol.54, (May 2006) Pages 1785-1789, ISSN: ISSN: 1359-6462.

a Koike, J.; Ohyama, R.; Kobayashi, T.; Suzuki, M.\& Maruyama, K. (2003)Grain-boundary sliding in AZ31 Mg alloys at room temperature to $523 \mathrm{~K}$. Mater Trans, Vol.44, (Apr. 2003) Pages 445-451, ISSN: 1345-9678.

b Koike, J.; Kobayashi, T.; Mukai, T. ; Watanabe, H.; Suzuki, M.; Maruyama, K. \& Higashi, K. (2003) The activity of non-basal slip systems and dynamic recovery at room temperature in fine-grained AZ31B Mg alloys. Acta Mater., Vol. 51, (Apr. 2003) Pages 2055-2065, ISSN: 1359-6454.

Lee, C. ; Huang, J. \& Hsieh, P. (2006) Mg based nano-composites fabricated by friction stir processing. Scripta Mater., Vol. 54 ,(April 2006) Pages1415-1420, ISSN: 1359-6462.

Lee, J.; Seok, H.; Han, J. \& Chung, Y. (2001) Controlling the textures of the metal strips via the continuous confined strip shearing (C2S2) process. Mater. Res. Bull., Vol.36, (March 2001) Pages 997-1004., ISSN: 0025-5408.

Lee, J. ; Seok, H. \& Suh, J. (2002) Microstructural evolutions of the Al strip prepared by cold rolling and continuous equal channel angular pressing. Acta Mater., Vol.50, (Sept. 2002) Pages 4005-4019, ISSN: 1359-6454.

Li, Y.; Liu, Y.; Ngai , T.; Zhang, D.; Guo, G. \& Chen, W. (2004) Effects of die angle on microstructures and mechanical properties of AZ31 Mg alloy processed by equal channel angular pressing . Trans Nonferrous Met Soc China, Vol.14, (Feb. 2004) Pages 53-57, ISSN:1003-6326.

Lin, H.; Huang, J. \& Langdon, T. (2005) Relationship between texture and low temperature superplasticity in an extruded AZ31 Mg alloy processed by ECAP. Mater. Sci. Eng. A, Vol.402, (Aug. 2005) Pages 250-257, ISSN: 0921-5093. 
Liu, T.; Wang, Y. ; Wu, S.; Peng, R. ; Huang, C.; Jiang, C. \& Li, S. (2004) Textures and mechanical behavior of Mg- 3.3\% Li alloy after ECAP. Scripta Mater., Vol.51, (Nov. 2004) Pages 1057-1061, ISSN: 1359-6462.

Ma, A. ; Jiang, J. ;Saito, N.; Ichinori, S.; Yuan, Y. ; Yang, D. \& Nishida Y. (2009). Improving both strength and ductility of a Mg alloy through a large number of ECAP passes. Mater. Sci. Eng. A , Vol. 513-514 , (July 2009) Pages 122-127, ISSN: 0921-5093.

Mabuchi, M.; Iwsaki, H. ;Yanase, K.\& Higashi, K. (1997) Low temperature superplasticity in an AZ91 Mg alloy processed by ECAE. Scripta Mater., Vol.36, (March 1997) Pages 681-686, ISSN: 1359-6462.

Mabuchi, M.; Ameyama, K.; Iwasaki, H. \& Higashi, K. (1999) Low temperature superplasticity of AZ91 Mg alloy with non-equilibrium grain boundaries. Acta Mater., Vol.47,( May 1999) Pages 2047-2057, ISSN: 1359-6454.

Máthis, K.; Gubicza, J. \& Nam, N. H. (2005) Microstructure and mechanical behavior of AZ91 Mg alloy processed by equal channel angular pressing . J. Alloys Compd, Vol.394, (May 2005), Pages 194-199, ISSN: 0925-8388.

Matsubara, K.; Miyahara, Y. ; Horita, Z. \& Langon, T.G. (2003). Developing superplasticity in a $\mathrm{Mg}$ alloy through a combination of extrusion and ECAP. Acta Mater., Vol.51, (June 2003) Pages 3073-3084, , ISSN: 1359-6454.

May, J.; Höppel, H. W. \& Göken, M. (2005). Strain rate sensitivity of ultrafine-grained aluminium processed by severe plastic deformation. Scripta Mater.,Vol.53 (July 2005) Pages 189-194, ISSN: 1359-6462.

Meyers, M.; Mishra, A. \& Benson, D. (2006) The deformation physics of nanocrystalline metals: experiments, analysis, and computations. JOM, Vol.58, (April 2006) Pages 41-48, ISSN:1047-4838

Morisada, Y.; Fujii, H.; Nagaoka, T. \& Fukusumi, M. (2006) Nanocrystallized Mg alloy uniform dispersion of $\mathrm{C}_{60}$ molecules. Scripta Mater. , Vol.55, (Dec. 2006) Pages10671070, ISSN: 1359-6462.

Mukai, T.; Yamanoi, M.; Watanabe, H. \& Higashi, K. (2001) Ductility enhancement in AZ31 Mg alloy by controlling its grain structure. Scripta Mater., Vol.45, (July 2001) Pages 89-94, ISSN: 1359-6462.

Nishida, Y.; Arima, H.; Kim, J. \& Ando, T. (2001) Rotary-die equal-channel angular pressing of an $\mathrm{Al}-7$ mass\% Si - 0.35 mass\% Mg alloy. Scripta Mater., Vol. 45, (Aug. 2001) Pages 261-266, ISSN: 1359-6462.

Nordlien, J. H.; Ono, S. ; Masuko, N. \& Nisancioglu, K. (1997) A TEM investigation of naturally formed oxide films on pure Mg. Corros. Sci., Vol.39, (Aug. 1997) Pages 1397-1414, ISSN: 0010-938X.

Op'tHoog, C.; Birbilis, N. \& Estrin Y. (2008) Corrosion of pure mg as a function of grain size and processing route. Adv. Eng. Mater., Vol.10,(May 2008) Pages 579-582, ISSN:1438-1656.

Perez-Prado, M. ; Valle, D. \& Ruano, O. (2004) Grain refinement of Mg-Al-Zn alloys via accumulative roll bonding. Scripta Mater., Vol.51, (Nov. 2004) Pages 1093-1097, ISSN: 1359-6462.

Raab, G. ; Valiev, R. ; Lowe, T. \& Zhu, Y. (2004) Continuous Processing of Ultrafine Grained Al by ECAP Conform. Mater. Sci. Eng. A, Vol. 382 (Sept. 2004) Pages 30-34, ISSN: 0921-5093. 
Richert, M.; Stüwe, H. ; Zehetbauer, M. ; Richert, J.; Pippan, R., Motz, C. \& Schafler, E. (2003). Work hardening and microstructure of AlMg5 after severe plastic deformation by cyclic extrusion and compression. Mater. Sci. Eng. A, Vol.355, (Aug. 2003) Pages 180-185, ISSN: 0921-5093.

Rosochowski, A. \& Olejnik, L. (2002) Numerical and Physical Modeling of Plastic Deformation in 2-turn Equal Channel Angular Extrusion. Journal of Materials Processing Technology,Vol.125-126, (Sept. 2002) Pages 309-316, ISSN: 0924-0136.

Saito, Y.; Tsuji, N.; Utsunomiya, H.; Sakai, T.\& Hong, R.(1998) Ultra-fine grained bulk aluminum produced by accumulative roll-bonding (ARB) process. Scripta Mater., Vol.39, (Oct. 1998) Pages 1221-1227, ISSN: 1359-6462.

Saito, Y.; Utsunomiya,H., Tsuji, N. \& Sakai, T. (1999) Novel ultra-high straining process for bulk materials-development of the accumulative roll-bonding (ARB) process. Acta mater., Vol.47, (Jan. 1999) Pages 579-583, ISSN:1359-6454.

Saito, Y.; Utsunomiya, H.; Suzuki, H. \& Sakai, T. (2000) Improvement in the r-value of aluminum strip by a continuous shear deformation process. Scripta Mater., Vol.42, (June 2000) Pages 1139-1144, ISSN: 1359-6462.

Segal, V. ; Reznikov, V. ; Drobyshevskiy, A. \& Kopylov, V. (1981) Plastic working of metals by simple shear. Russian Metall, No.1, Pages 99-105, ISSN: 0036-0295.

Song,D.; Ma, A.; Jiang, J.; Lin, P.; Yang, D. \& Fan, J. (2010) Corrosion behavior of equalchannel-angular-pressed pure magnesium in $\mathrm{NaCl}$ aqueous solution. Cor. Sci., Vol. 52, (Febr.) Pages 481-490, ISSN: 0010-938X

Suresh, S. (1998). Fatigue of materials. Cambridge University Press, ISBN: 0521570468, Cambridge.

Takayama, Y.; Saigo, Y.; Takahashi, R. \& Kato, H. (2002) . Changes in microstructure and crystallite orientation distribution by continuous cyclic bending and annealing in a commercial purity titanium. J. Jpn. Inst. Light Met., Vol. 52 , Pages 566-571, ISSN: 0451-5994.

Tong, L.; Zheng, M.; Chang, H.; Hu, X. \& Wu, K. (2009) Microstructure and mechanical properties of $\mathrm{Mg}-\mathrm{Zn}-\mathrm{Ca}$ alloy processed by equal channel angular pressing. Mater. Sci. Eng. A, Vol.523, (Oct. 2009) Pages 289-294, ISSN: 0921-5093.

Tsuji , N.; Saito, Y.; Lee, S. \& Minamino, Y. (2003) ARB (Accumulative Roll-Bonding) and other new techniques to produce bulk ultrafine grained materials. Adv. Eng. Mater. Vol.5, (Jun. 2003) Pages 338-344, ISSN: 1438-1656.

Uhlenhaut, D. I.; Furrer, A.; Uggowitzer P. J. \& Löffler, J. F. (2009) Corrosion properties of glassy Mg70Al15Ga15 in $0.1 \mathrm{M} \mathrm{NaCl}$ solution . Intermetallics, Vol.17, (Oct.2009)Pages 811-817, ISSN:0966-9795.

Valiev, R. ; Krasilnikov, N. \& Tsenev, N. (1991) Plastic Deformation of Alloys with Submicron-grained Structure. Mater. Sci. Eng. A, Vol.197, (May 1991) Pages 35-40, ISSN: 0921-5093.

Valiev, R.; Islamgaliev, R. \& Alexandrov, I. (2000) Bulk nanostructured materials from severe plastic deformation. Prog. Mater. Sci. Vol. 45, Pages 103-189, ISSN: 0079-6425.

Valiev, R. \& Langdon, T. (2006) Principles of equal-channel angular pressing as a processing tool for grain refinement. Prog. Mater .Sci., Vol.51, (Sep. 2006) Pages 881-981, ISSN: 0079-6425. 
Valiev, R. \& Nazarov, A. (2009). Bulk nanostructured materials by SPD processing, In: Bulk nanostructured materials, Zehetbauer, M.J. \& Zhu, Y.T.(ed.), 21-48,Willey-VCH, ISBN:978-527-315246, Weinheim.

Vinogradov, A.; Nagasaki, S.; Patlan, V. ; Kitagawa, K. \& Kawazoe, M. (1999). Fatigue properties of $5056 \mathrm{Al}-\mathrm{Mg}$ alloy produced by equal-channel angular pressing. Nanostruct Mater, Vol.11, (Oct. 1999) Pages 925-934, ISSN: 0965-9773.

Volovitch, P.; Allely, C. \& Ogle, K. (2009) Understanding corrosion via corrosion product characterization: I. Case study of the role of $\mathrm{Mg}$ alloying in $\mathrm{Zn}-\mathrm{Mg}$ coating on steel . Corros. Sci., Vol. 51, (June 2009) Pages 1251-1262, ISSN: 0010-938X.

Weertman, J. ; Farkas, D.; Hemker, K; Kung, H.; Mayo, M. \& Mitra, R. (1999). Structure and mechanical behavior of bulk nanocrystalline materials . Mater Res Soc Bull, Vol.24, Pages 44-50, ISSN: 0883-7694.

Yamakov, V.; Wolf, D.; Phillpot, S., Mukherjee, A. \& Gleiter, H. (2004). Deformationmechanism map for nanocrystalline metals by molecular-dynamics simulation. Nature Mater., Vol.3, (Dec. 2003) Pages 43-47, ISSN: 1476-1122.

Yapici, G. \&Karaman, I. (2009) Common trends in texture evolution of ultra-fine-grained hcp materials during equal channel angular extrusion. Mater. Sci. Eng. A, Vol. 503, (Mar. 2009) Pages 78-81, ISSN: 0921-5093.

Yoshida, Y.; Cisar, L.; Kamado, S.; Koike, J. \& Kojima, Y. (2003) Texture Development of AZ31 Mg Alloy during ECAE Processing. Mater Sci Forum, Vol. 419-422, (Jan. 2003) Pages 533-538, ISSN: 0255-5476.

Zheng, M.; Xu, S.; Qiao, X.; Wu, K.; Kamado, S. \& Kojima, Y.(2008) Compressive deformation of $\mathrm{Mg}-\mathrm{Zn}-\mathrm{Y}-\mathrm{Zr}$ alloy processed by equal channel angular pressing . Mater. Sci. Eng. A, Vol. 483-484, (June 2008) Pages 564-567, ISSN: 0921-5093.

Zhilyaev, A. \& Langdon T. (2008) Using high-pressure torsion for metal processing: Fundamentals and applications. Prog. Mater .Sci., Vol. 53, (Aug. 2008) Pages 893979, ISSN: 0079-6425.

Zhu, Y.; Huang, J.; Gubicza, J.; Ungár, T.; Wang, Y.; Ma,. E. \& Valiev, R. (2003) Nanostructures in Ti processed by severe plastic deformation. J. Mater Res.,Vol.18, (Aug. 2003) Pages 1908-1917, ISSN: 1862-5282.

Zúberová, Z.; Kunz, L.; Lamark, T.; Estrin, Y. \& Janeček, M. (2007) Fatigue and tensile behavior of cast, hot-rolled, and severely plastically deformed AZ31 Mg alloy. Metall Mater Trans, Vol. 38, ( Sept. 2007) Pages 1934-1940, ISSN: 1073-5623. 


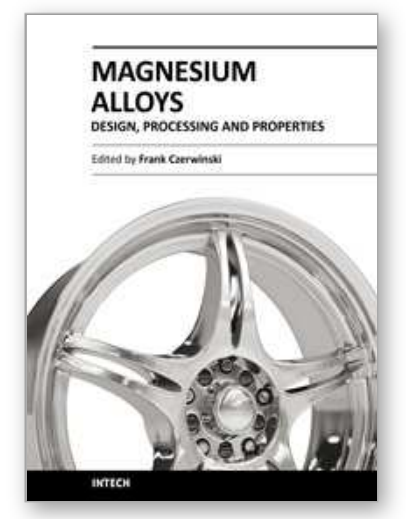

\author{
Magnesium Alloys - Design, Processing and Properties \\ Edited by Frank Czerwinski
}

ISBN 978-953-307-520-4

Hard cover, 526 pages

Publisher InTech

Published online 14, January, 2011

Published in print edition January, 2011

Scientists and engineers for decades searched to utilize magnesium, known of its low density, for lightweighting in many industrial sectors. This book provides a broad review of recent global developments in theory and practice of modern magnesium alloys. It covers fundamental aspects of alloy strengthening, recrystallization, details of microstructure and a unique role of grain refinement. The theory is linked with elements of alloy design and specific properties, including fatigue and creep resistance. Also technologies of alloy formation and processing, such as sheet rolling, semi-solid forming, welding and joining are considered. An opportunity of creation the metal matrix composite based on magnesium matrix is described along with carbon nanotubes as an effective reinforcement. A mixture of science and technology makes this book very useful for professionals from academia and industry.

\title{
How to reference
}

In order to correctly reference this scholarly work, feel free to copy and paste the following:

Aibin Ma and Jinghua Jiang (2011). Bulk Ultrafine-grained Magnesium Alloys by SPD Processing Technique, Microstructures and Properties, Magnesium Alloys - Design, Processing and Properties, Frank Czerwinski (Ed.), ISBN: 978-953-307-520-4, InTech, Available from: http://www.intechopen.com/books/magnesium-alloysdesign-processing-and-properties/bulk-ultrafine-grained-magnesium-alloys-by-spd-processing-techniquemicrostructures-and-properties

\section{INTECH}

open science | open minds

\author{
InTech Europe \\ University Campus STeP Ri \\ Slavka Krautzeka 83/A \\ 51000 Rijeka, Croatia \\ Phone: +385 (51) 770447 \\ Fax: +385 (51) 686166 \\ www.intechopen.com
}

\author{
InTech China \\ Unit 405, Office Block, Hotel Equatorial Shanghai \\ No.65, Yan An Road (West), Shanghai, 200040, China \\ 中国上海市延安西路65号上海国际贵都大饭店办公楼 405 单元 \\ Phone: +86-21-62489820 \\ Fax: +86-21-62489821
}


(C) 2011 The Author(s). Licensee IntechOpen. This chapter is distributed under the terms of the Creative Commons Attribution-NonCommercialShareAlike-3.0 License, which permits use, distribution and reproduction for non-commercial purposes, provided the original is properly cited and derivative works building on this content are distributed under the same license. 